\title{
Voidage profiles in magnetically fluidized beds
}

\author{
Yung-Chung Lin, Lii-Ping Leu* \\ Department of Chemical Engineering, National Taiwan University, Taipei 106-17, Taiwan
}

Received 1 February 2000; received in revised form 1 October 2000; accepted 16 January 2001

\begin{abstract}
Voidage profiles in a fluidized bed of iron particles $(230 \mu \mathrm{m})$ were investigated under the influence of an external uniform axial magnetic field. Passing a direct current through five solenoids generated uniform magnetic field. The five solenoids were arranged elaborately to get larger uniform magnetic space than that generated by Helmholtz electromagnet coils. A sensitive optical measuring system, based on detection of light reflected by particles, was used to measure local voidage in both dense and dilute phases.

Local voidage was measured as a function of superficial fluidizing air velocity, magnetic field intensity and the position in the bed. At a given magnetic field intensity and at the same position in the bed, the voidage was constant for a low air velocity range (in a fixed bed). The local voidage changed irregularly with increasing air velocity for an intermediate air velocity range (in a magnetically stabilized fluidized bed, MSFB). The local voidage changed linearly with increasing air velocity for a slightly high air velocity range (in a magnetized bubbling fluidized bed, MBFB). A general correlation was developed to predict the local solids fraction at the arbitrary position in the bed: $(1-\varepsilon)=(1-\varepsilon)_{\mathrm{c}}+\left[(1-\varepsilon)_{\mathrm{w}}-(1-\varepsilon)_{\mathrm{c}}\right](r / R)^{B}$ where $(1-\varepsilon),(1-\varepsilon)_{\mathrm{c}}$ and $(1-\varepsilon)_{\mathrm{w}}$ represent the local solids fraction at arbitrary position in the bed, at the bed center and on the bed wall; and $B,(1-\varepsilon)_{\mathrm{c}}$ and $(1-\varepsilon)_{\mathrm{w}}$ are the function of air velocity, distance from the distributor and magnetic field intensity. (C) 2001 Elsevier Science B.V. All rights reserved.
\end{abstract}

Keywords: Fluidized beds; Magnetically fluidized beds; Voidage; Optical fiber probe

\section{Introduction}

A fluidized bed of magnetizable particles under the influence of an external magnetic field is called a magnetofluidized bed (MFB). An MFB is a fluid-solids contactor, which shares a number of advantages of both packed bed and fluidized bed at the same time. Similar to fluidized beds, the solids in an MFB resemble a liquid and are easily transported between vessels. The loading of solids is also easier as the solids move in and out of the bed continuously. Because the magnetic forces in an MSFB suppress the formation of bubbles, its contacting efficiencies is close to those to that of a fixed bed without gas bubbling and solid back mixing. Local temperatures and particle distributions in MFBs are much more uniform than those in fixed beds. The gas phase flows through the MSFB in nearly plug flow, so similar to fixed beds, it has a narrow residence time distribution. MFBs are used exten- sively in affinity chromatography [1-3], aerosol filtration [4,5], particle separation [6-10], biological separation [1113], gas separation [14,15], ammonia synthesis [16], and ethanol fermentation [17]. Structural considerations of MFBs are essential to identifying the optimal operating conditions for applications.

There are two kinds of experimental techniques to study the bed structure: one is to estimate the bed voidage from the measurement of the pressure drop across a known difference of height $[4,18]$. The other is to estimate the bed voidage from the measurement of bed magnetic permeability [19]. ${ }^{1}$ However, these two methods only can offer global bed voidage. Although the past research has been done on local bed voidage in circulating fluidized beds by using reflective optical probe systems [20-25], no work has been done on local bed voidage in an MFB. In the present investigation, reflective optical probe was used to measure the local bed voidage of MFBs in order to get more realization about the structure of MFBs. An improvement has been made on the calibration of the optical probe

\footnotetext{
* Corresponding author. Tel.: +886-2-363-5230; fax: +886-2-3623040.

E-mail address: 1leulii@ @cms.ntu.edu.tw (L.-P. Leu).
}

\footnotetext{
${ }^{1}$ This is cited as Sonolikar's work.
} 
that made it possible to measure and calculate local solids fraction in both dense and dilute phases by interpolation. In addition, detailed measurements of local solids fraction for several operating conditions were performed in order to gain a general equation of radial solids fraction profiles.

\section{Experimental facility}

The experimental facility consists of an air supply system, a fluidization column, a specially designed electromagnet with a Takasago EX-750L D.C. power supply, an off-gas cleaning system, three pressure transducers, an FFT analyzer and a photon counter connected to data acquisition system, shown schematically in Fig. 1. The fluidization column is constructed from a $1-\mathrm{cm}$ thickness and $100-\mathrm{cm}$ length transparent Plexiglas pipe of $5-\mathrm{cm}$ inner diameter (i.d). The column is equipped with a perforated distributor of $4.96 \%$ open area. Five $22.6-\mathrm{cm}$ i.d. and $2-\mathrm{cm}$ axial width solenoids, which consisted of 2663 turns of 19 SWG magnet wire were used for generation of an axial magnetic field. The distance between the midpoints of axial width of two solenoids is 11.3 or $5.8 \mathrm{~cm}$.
The solenoids are designed to produce a constant maximum magnetic field up to $19305 \mathrm{~A} / \mathrm{m}$. The magnetic field intensity is varied by changing the electric current fed to the solenoids, and is measured by a self-calibrating gaussmeter (F.W. Bell model 9200). The heterogeneity, in the radial and axial direction for a cylindrical volume, which is $19 \mathrm{~cm}$ in height and $7 \mathrm{~cm}$ in diameter, does not exceed $1 \%$ of magnetic intensity at the central position within the solenoids. The center of symmetry of the magnetic system is at the height of $13 \mathrm{~cm}$ above the distributor. The heterogeneity does not exceed at most $1.5 \%$ of magnetic intensity at the central position within the solenoids in a 7-cm i.d. $\times 27-\mathrm{cm}$ cylindrical volume.

The detailed procedure adopted to align the electromagnet and measure the magnetic field intensity in the central region is elaborated below. The electromagnet assembly is shown in Fig. 2. The center of symmetry of the magnetic system, the origin $(0,0)$ of this coordinate system, is the center of the middle solenoid.

Comparison of uniform space size for four types of electromagnet coils is presented in Table 1. Variations of magnetic field intensity along the $x$ and $y$ axes at $1.2 \mathrm{~A}$ for types 4 and 2 are shown in Figs. 2 and 3, respectively.

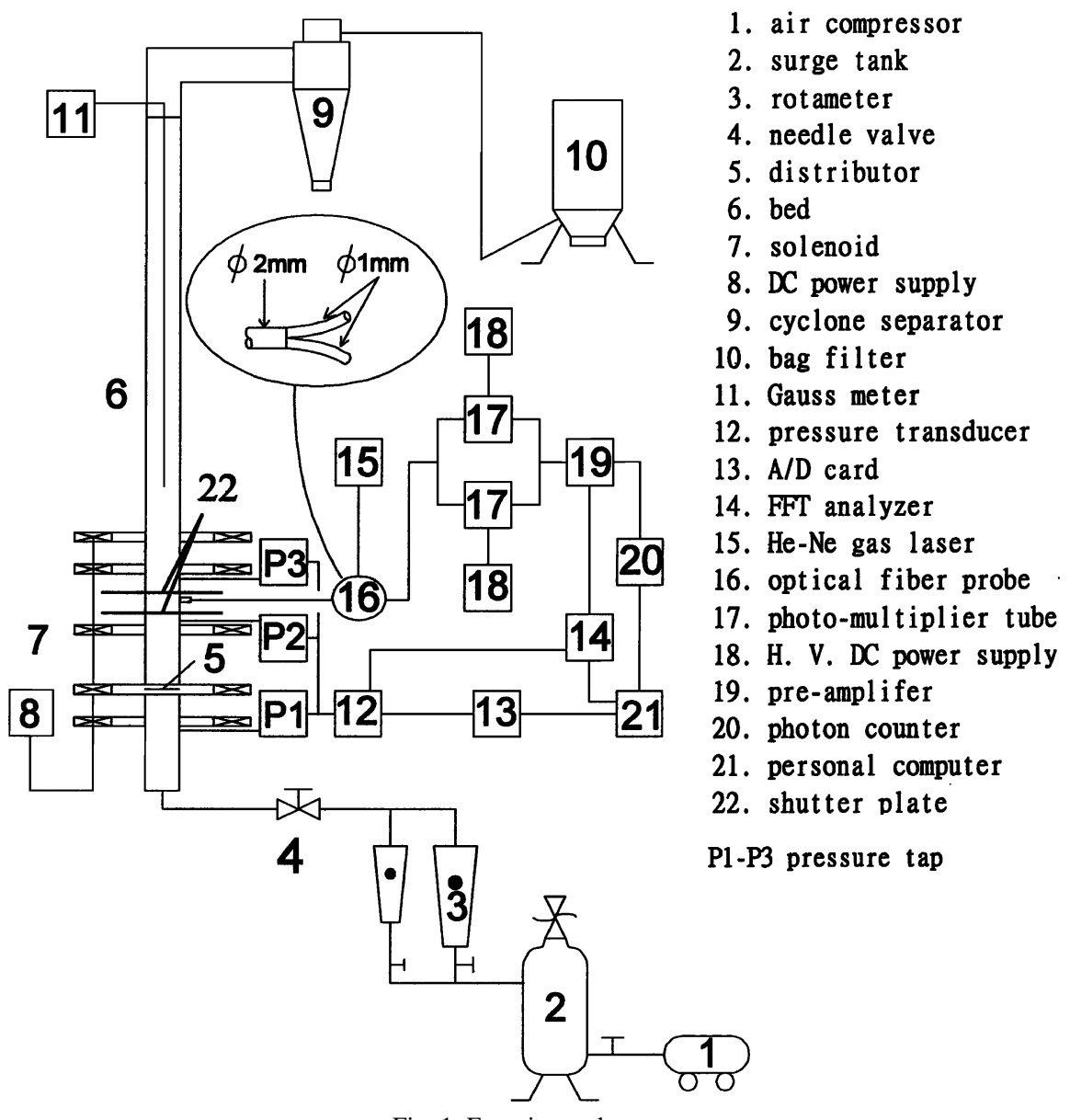

1. air compressor

2. surge tank

3. rotameter

4. needle valve

5. distributor

6. bed

7. solenoid

8. DC power supply

12. pressure transducer

13. A/D card

14. FFT analyzer

15. He-Ne gas laser

16. optical fiber probe

17. photo-multiplier tube

18. H. V. DC power supply

19. pre-amplifer

20. photon counter

21. personal computer

22. shutter plate

\section{P1-P3 pressure tap}

Fig. 1. Experimental setup. 


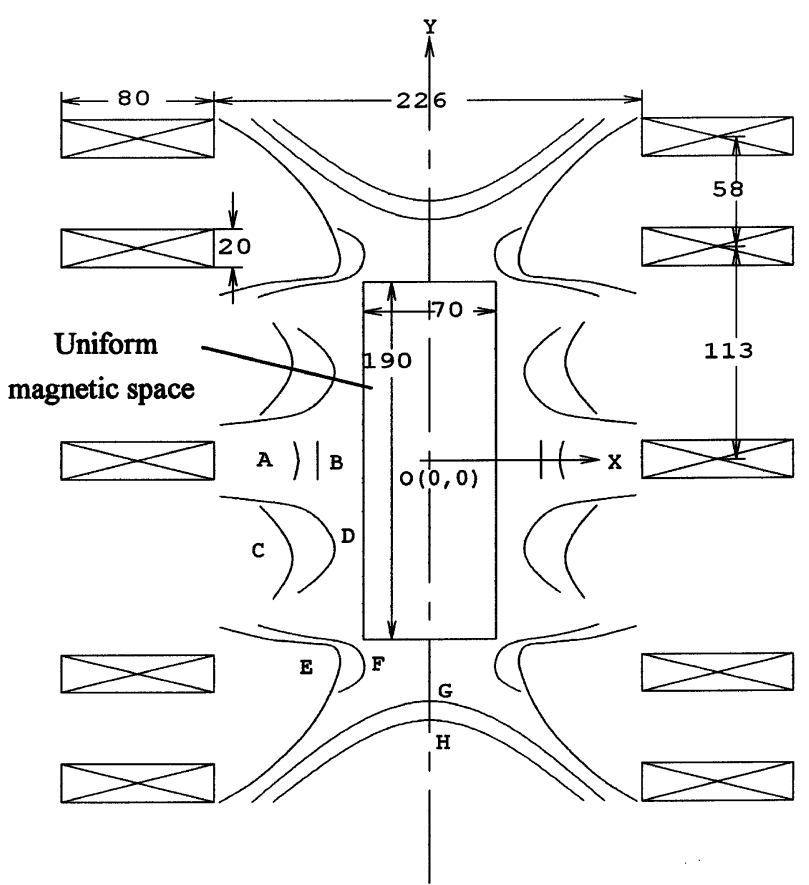

Fig. 2. Magnetic field distribution of type 4 electromagnet. All dimensions are in $\mathrm{mm}$. (O: $12919 \mathrm{~A} / \mathrm{m}, \mathrm{A} / \mathrm{O}=1.02, \mathrm{~B} / \mathrm{O}=1.01, \mathrm{C} / \mathrm{O}=0.97$, $\mathrm{D} / \mathrm{O}=0.99, \mathrm{E} / \mathrm{O}=1.03, \mathrm{~F} / \mathrm{O}=1.02, \mathrm{G} / \mathrm{O}=0.99, \mathrm{H} / \mathrm{O}=0.97)$.

As the variations along the $x$ and $y$ axes are less than $\pm 1.5 \%$ of central position, the variations are negligibly small and the magnetic field intensity of space can be regarded as uniform. The $\pm 1 \%$ variations of central position uniform magnetic field intensity space for every type are shown in Fig. 4.

Table 1 shows the length of uniform magnetic space of type 4 is 3.8 times of that of type 2 (Helmholtz electromagnet coils). Type 4 gives the longest uniform magnetic space. If we want to make $190 \mathrm{~mm}$ in length uniform space like type 4 with Helmholtz electromagnet coils, may be we must make $266 \times 190 \mathrm{~mm}$ uniform space, which need larger solenoids and the solenoids must be cooled. Comparing with Helmholtz electromagnet coils, for same long uniform space, type 4 has the following three advan-

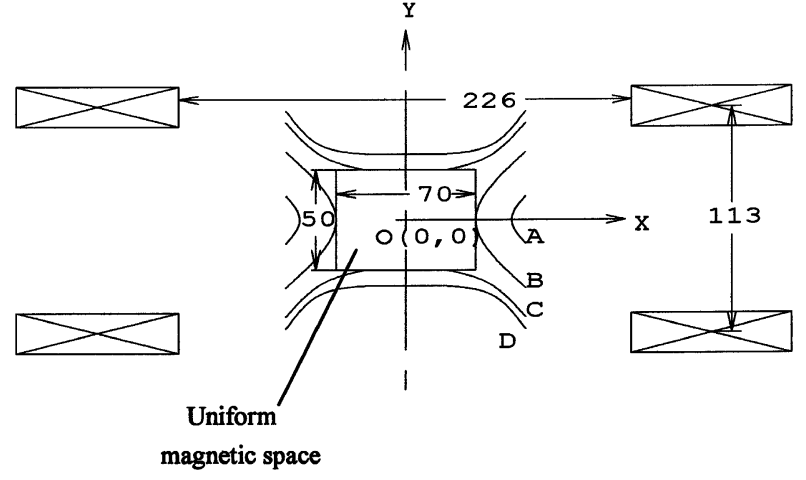

Fig. 3. Magnetic field distribution of Helmholtz electromagnet (type 2). All dimensions are in $\mathrm{mm}$. (O: $7697 \mathrm{~A} / \mathrm{m}, \mathrm{A} / \mathrm{O}=1.02, \mathrm{~B} / \mathrm{O}=1.01$, $\mathrm{C} / \mathrm{O}=0.99, \mathrm{D} / \mathrm{O}=0.98$ ).

tages: less mass, easy to move and to dissipate heat naturally.

At the central position, $(0,0)$ of the type 4 electromagnet coils, the variation of $\mathrm{H}$ as a function of the total current fed to the solenoids is shown in Fig. 5. Regression analysis of the data yielded the following good linear relation:

$H(\mathrm{~A} / \mathrm{m})=2145 I(\mathrm{~A})$.

The optical fiber probe consists of a pair of 1-mm core-diameter plastic optical fibers: one from the light source and the other to light receiver. The tips of the two optical fiber probes were connected to the same side of 2-mm-diameter optical fiber in order that inlet light and reflective light past the same path.

The probe was installed at a level of $5.9,16.6$ or 42.4 $\mathrm{cm}$ above the distributor of the bed, and could be moved horizontally for measurements at different radial positions. $1706.1 \mathrm{~g}$ of iron particles was fed to the fluidization column. The static bed height $\left(h_{\mathrm{s}}\right)$ was $18.9 \mathrm{~cm}$. The measured voidage was the local, time-averaged value over $4 \mathrm{~s}$ for each radial position. Particle concentration was measured at eight radical positions between the bed wall and the center of the bed, because eight points were

Table 1

Comparison of uniform magnetic space for four types of electromagnet coils (all with same current and voltage)

\begin{tabular}{lllll}
\hline Electromagnet type & $\begin{array}{l}\text { Number of } \\
\text { parallel coils }\end{array}$ & $\begin{array}{l}\text { Distance between } \\
\text { coils }(\mathrm{mm})\end{array}$ & $\begin{array}{l}\text { Uniform magnetic } \\
\text { space obtained } \\
\text { (diameter } \times \text { length, mm) }\end{array}$ & $\begin{array}{l}\text { Ratio of length of } \\
\text { uniform magnetic space } \\
\text { (length of any type/ } \\
\text { length of type 2) }\end{array}$ \\
\hline 1 & 1 & - & $22 \times 15$ & 0.3 \\
2 (Helmholtz type) & 2 & 113 & $70 \times 50$ & 1 \\
3 (Like Helmholtz type) & 5 & 113 & $70 \times 80$ & 1.6 \\
4 (This study) & 5 & 113 or 58 & $70 \times 190$ & 3.8 \\
\hline
\end{tabular}




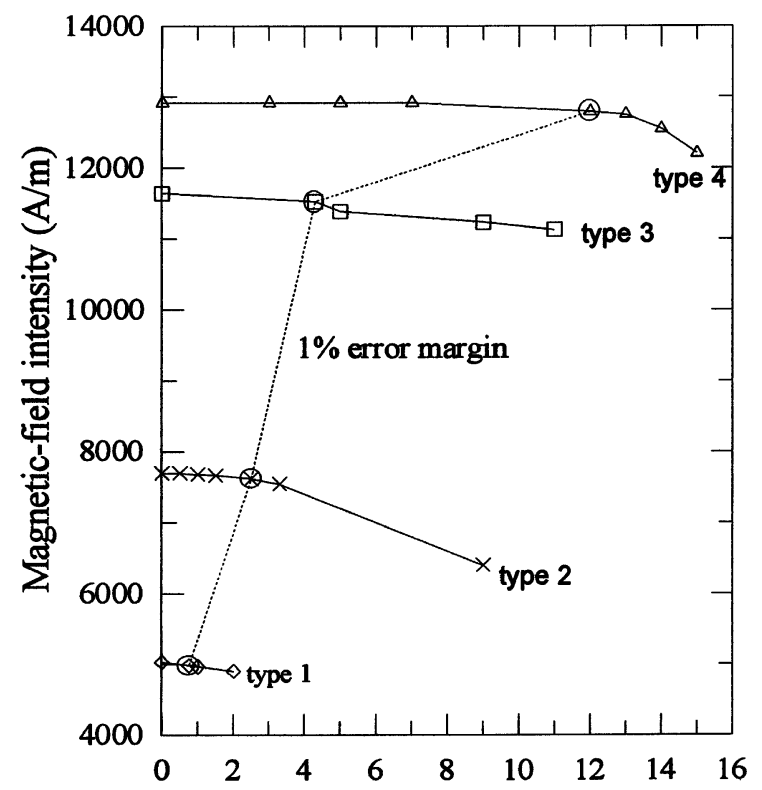

Distance $(\mathrm{cm})$ along the axial position of column

Fig. 4. Variation of magnetic-field intensity along the axial position of column.

considered sufficient to construct the voidage profile in the bed of $5-\mathrm{cm}$ i.d. When the variation of bed pressure with gas velocity (Fig. 11) or the variation of solids fraction at the bed center with gas velocity (Fig. 13) was measured, the magnetic field was applied to a static powder bed before fluidization. The mode of operation is the 'magnetization FIRST' mode according to the classification of Hristov [26]. When radial solids fraction profile was measured, the magnetic field was applied at fixed gas velocity on particles, which are already fluidized, i.e. the 'magneti-

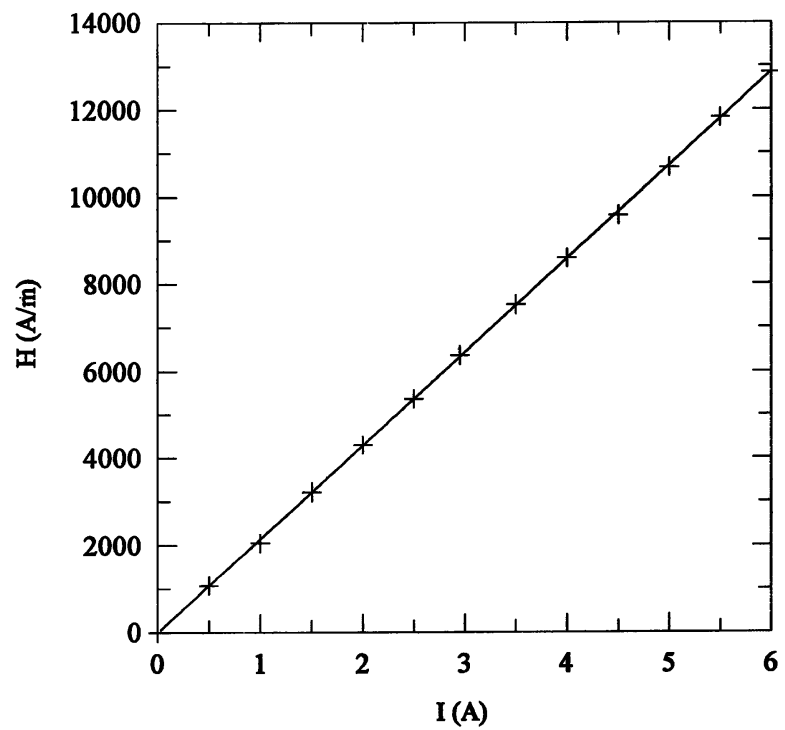

Fig. 5. Magnetic field intensity at point $(0,0)$ of type 4 electromagnet coils as a function of current.
Table 2

The properties of solid particles used

\begin{tabular}{ll}
\hline Solid particles & Iron \\
\hline Classification of Geldart Particle & Group B \\
Shape & Spherical \\
Size range $(\mu \mathrm{m})$ & $212-250$ \\
Mean diameter $(\mu \mathrm{m})$ & 230 \\
True density $\left(\mathrm{kg} / \mathrm{m}^{3}\right)$ & 7860 \\
Minimum fluidization velocity, & 0.135 \\
$U_{\mathrm{mf}}(\mathrm{m} / \mathrm{s})^{\mathrm{a}}$ & \\
Terminal velocity, $V_{\mathrm{t}}(\mathrm{m} / \mathrm{s})^{\mathrm{b}}$ & 4.276 \\
\hline
\end{tabular}

${ }^{\mathrm{a}}$ Measured value without applying magnetic field.

${ }^{\mathrm{b}}$ Calculated value [27].

zation LAST' mode. The properties of solid particles used in this study are listed in Table 2 .

\section{Calibration of particle concentration}

\subsection{Calibration of the optical probe}

As no method for direct conversion of reflective light count to particle concentration exists, a technique similar to those used by Matsuno et al. [28] and Herbert et al. [22] was used to calibrate the optical fiber probe. Free-falling particles falling at certain velocity, the particle concentration can be calculated by Eq. (2).

$1-\varepsilon=\dot{m} /\left(V_{\mathrm{p}} A \rho_{\mathrm{p}}\right)$,

where $\varepsilon=$ voidage $(-), \dot{m}=$ particle mass flow rate $(\mathrm{kg} / \mathrm{s})$, $V_{\mathrm{p}}=$ particle velocity $(\mathrm{m} / \mathrm{s}), A=$ tube cross-sectional area $\left(\mathrm{m}^{2}\right), \rho_{\mathrm{p}}=$ particle density $\left(\mathrm{kg} / \mathrm{m}^{3}\right)$.

As shown in Fig. 6, the probe calibration equipment consists of a metal circle, a sieve, and a can. Solid particles flow from a funnel inside metallic circle, through a hole in the center of Plexiglas plate below the sieve, and then the solid particles fall into a collection can. Collecting the particles and weighing over a known time period determined the mass flow rate of solid particles.

In this study, a piece of wood was drilled a $2.35-\mathrm{cm}-\mathrm{di}-$ ameter hole. A Plexiglas plate with thickness of $1 \mathrm{~mm}$, which was drilled a $1.04-\mathrm{cm}$-diameter hole was glued to the top of the wood with thickness of $7.1 \mathrm{~mm}$. To reduce the error that results from velocity distribution of particles, the thickness of Plexiglas plate and the diameter of hole must be small. The side of wood was drilled a 3.2-mm-diameter hole in order to insert the optical fiber probe. The particle concentration can be varied by using the sieve of different apertures and was measured at $3.6 \mathrm{~mm}$ below the sieve where the optical fiber probe was fixed. The particle free-fall velocity was computed by using the fourth-order Runge-Kutta method. 
The sampling frequency was set at $50 \mathrm{~Hz}$ and 200 points were sampled. By linear regression in logarithmic coordinates (Fig. 7), the relationship of solids fraction and signal intensity is expressed as follows:

$1-\varepsilon=0.5849 \bar{S}^{1.734}$,

$\bar{S}=\frac{S-S_{\mathrm{v}}}{S_{\mathrm{f}}-S_{\mathrm{v}}}$,

where $\bar{S}=$ normalized signal intensity $(-) ; S=$ signal intensity at any position (count); $S_{\mathrm{v}}=$ signal intensity in void bed $(1-\varepsilon=0)$ (count); $S_{\mathrm{f}}=$ signal intensity in fixed bed $(1-\varepsilon=0.5849)$ (count).

The solids fraction of fixed bed was measured as follows. Pouring $910.3 \mathrm{~g}$ iron particles into a $200 \mathrm{~cm}^{3}$ graduated cylinder gave $198 \mathrm{~cm}^{3}$ volume. The solids fraction was calculated by using the below equation:

$1-\varepsilon=m /\left(V \rho_{\mathrm{p}}\right)=910.3 /(198 \times 7.86)=0.5849$,

where $m=$ total mass of particles $(\mathrm{g}) ; V=$ total volume of particles $\left(\mathrm{cm}^{3}\right)$.

The signal intensity of reflective optical fiber probe is very sensitive to the little change of particle concentration; therefore, it can be extensively used in both dense and dilute phases.

\subsection{Verification of the calibration results}

Since the local solids fraction was measured, the average solids fraction is estimated by dividing the bed section into $n$ concentric rings and calculating the weighted sum

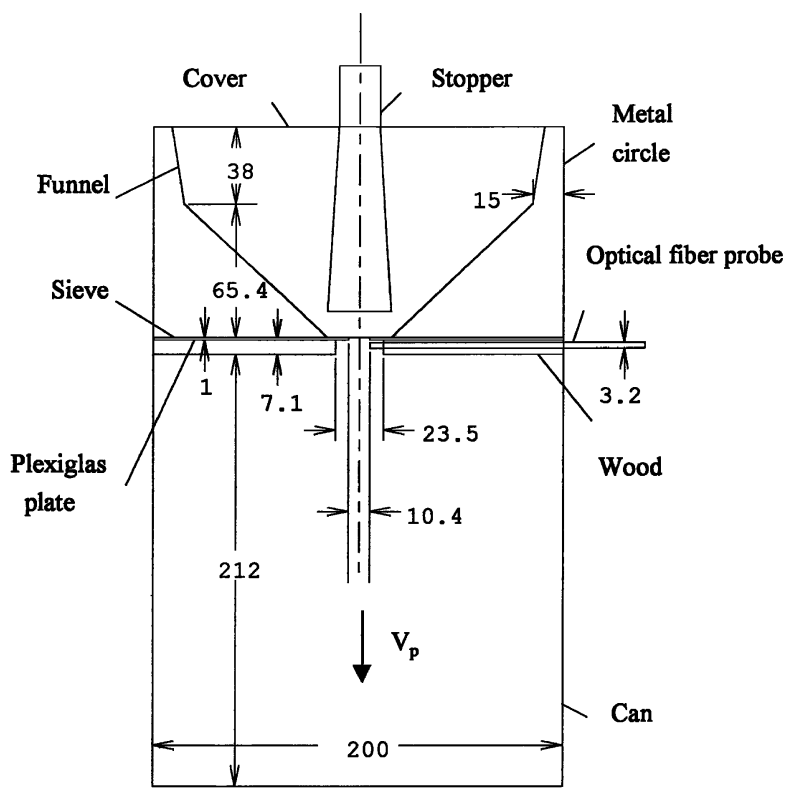

Fig. 6. Calibration equipment for particle concentration. All dimensions are in $\mathrm{mm}$.

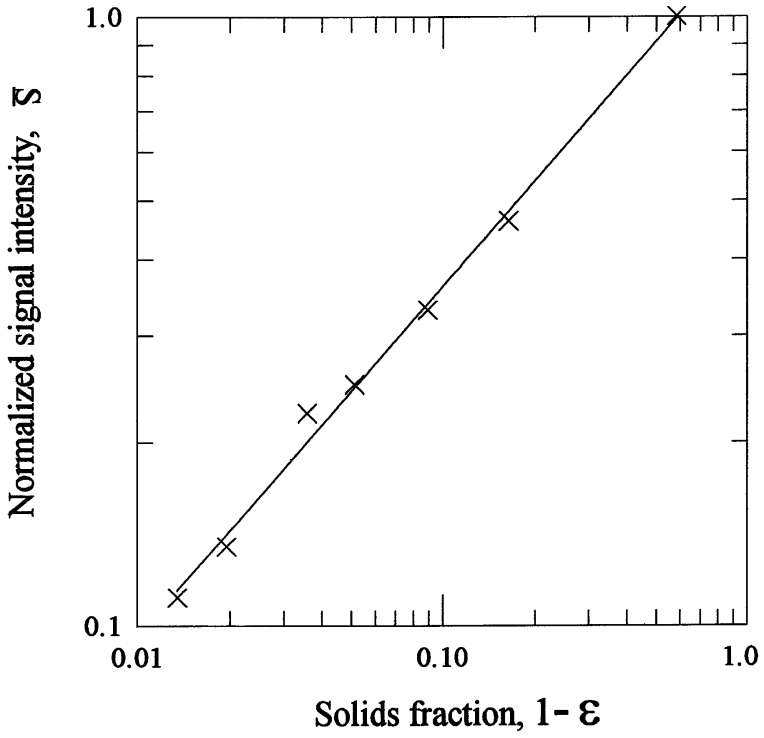

Fig. 7. Calibration curve for iron particles.

of the solids fraction in each ring with respect to its surface area [22]:

$1-\bar{\varepsilon}=\sum_{i=0}^{n}\left[\left(r_{i+1} / R\right)^{2}-\left(r_{i} / R\right)^{2}\right](1-\varepsilon)_{i+1}$,

where $\bar{\varepsilon}=$ voidage averaged over bed cross-section (-); $\varepsilon=$ local, time-averaged voidage in bed $(-) ; r=$ radial coordinate $(\mathrm{m}) ; R=$ radius of bed $(\mathrm{m})$.

The cross-sectionally averaged solids fractions determined using the above relationship are compared with the experimental data obtained from shutter measurement. Two shutter plates located above and below the optical probe $(z=16.6 \mathrm{~cm})$ are installed horizontally at $2.1-\mathrm{cm}$ intervals $(z=15.6,17.7 \mathrm{~cm})$. Details of the shutter design are substantially similar to that used in the earlier work of Morooka et al. [29]. When the gas flow was stopped, the shutter plates were closed simultaneously. Knowing the mass of the trapped solid particles, the cross-sectionally averaged solids fraction $(1-\bar{\varepsilon})$ can be obtained by using the following relation:

$1-\bar{\varepsilon}=m_{\mathrm{p}} /\left(\rho_{\mathrm{p}} A \Delta L\right)$,

where $m_{\mathrm{p}}=$ trapped particles mass $(\mathrm{kg}) ; \rho_{\mathrm{p}}=$ particle density $\left(\mathrm{kg} / \mathrm{m}^{3}\right) ; A=$ bed cross-sectional area $\left(\mathrm{m}^{2}\right) ; \Delta L=$ distance between shutter plates (m).

The parity of solids fraction from shutter and optical fiber probe measurements is shown in Fig. 8. There is an excellent agreement between the two methods.

Neglecting wall friction and acceleration forces in dilute phase, the pressure drop over a certain section of a column can be attributed to gravity force. The cross-sectionally averaged solids fraction $(1-\bar{\varepsilon})$ in dilute phase can be obtained by using the following relation:

$\Delta P=\rho_{\mathrm{p}} g(1-\bar{\varepsilon}) \Delta L$, 


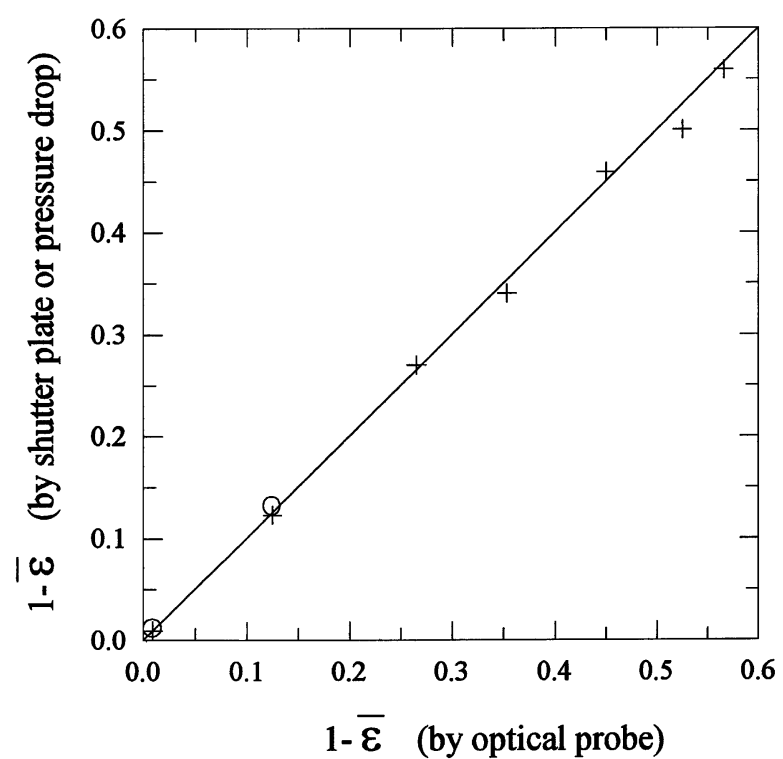

Fig. 8. Parity plot of solids fraction from shutter plate $(+)$, pressure drop (O) and optical fiber probe measurements.

where $\Delta P=$ pressure drop $(\mathrm{Pa}) ; g=$ acceleration due to gravity $\left(\mathrm{m} / \mathrm{s}^{2}\right) ; L=$ distance between pressure probes $(\mathrm{m})$.

The parity of solids fraction from pressure drop and optical fiber probe measurements in dilute phase is shown in Fig. 8. There is an excellent agreement between the two methods in dilute phase.

\section{Results and discussion}

\subsection{The instantaneous change of particle concentration}

The instantaneous change of particle concentration at the center of bed column is shown in Fig. 9. Lower voltage stood for larger particle concentration, so the peaks in Fig. 9 stood for low particle concentration (i.e. bubble). The peaks in Fig. 9(b) and (c) were fewer and sharper than those in Fig. 9(a) showed that the low particle concentration with applying magnetic field was less than that without applying magnetic field. These are similar to that the average bubble diameter at given fluidization velocity decreases with the increase of magnetic field intensity [30]. Fig. 9(d) revealed that the peaks disappeared and the solids fraction at a constant gas velocity remained constant in a magnetically stabilized fluidized bed (MSFB).

The probability density function (p.d.f.) and cumulative distribution function (c.d.f.) of 2048 voidage signals with equal voltage interval $(0.000244141 \mathrm{~V})$ at various magnetic field intensities is shown in Fig. 10. The distribution of p.d.f from (a) to (d) became sharp and the peaks at the right moved to the left showed that the variation of voidage became small with increasing magnetic field intensity and the number of bubbles decreased with increasing magnetic field intensity. The c.d.f. shows that the frequency of lower voltage (larger particle concentration) increased from around $70 \%$ in the bubbling fluidized bed to $100 \%$ in the MSFB.

\subsection{Pressure drop-velocity diagram of $M F B$}

For the convenience of discussing the effect of gas velocity on particle concentration, the definition of several relative symbols of gas velocities is shown in Fig. 11. $U_{\mathrm{mf}}$ is the minimum fluidization velocity without applying magnetic field obtained from the graphical method of Davidson and Harrison. $U_{\mathrm{e}}$ is the incipient expansion velocity. $U_{\mathrm{t}}$ is the transition velocity (gas velocity at the upper limit of magnetic stabilization; i.e. the magnetic field can no longer suppress bubble formation) obtained from the sudden increase of standard deviation (STD) of pressure drop fluctuations. This is different from the method of Puncochar et al. [31]. They determined the $U_{\mathrm{mf}}$ without applying magnetic field from the linear relationship between STD of pressure drop fluctuations and gas velocity. With applying magnetic field, owing to the increase of the STD of pressure drop fluctuations at $U_{\mathrm{t}}$ is sudden, the relationship between STD of pressure drop fluctuations and gas velocity is not linear.
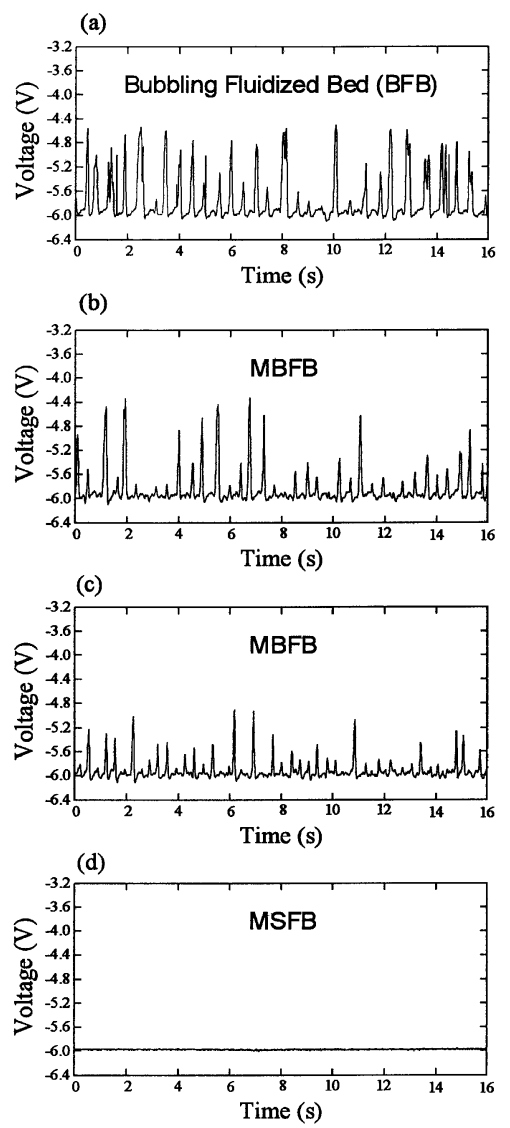

Fig. 9. Wave forms of voidage signal at various magnetic field intensities. Higher voltage stands for larger voidage. $\left[U_{\mathrm{s}} / U_{\mathrm{mf}}=1.75, z / h_{\mathrm{s}}=0.878\right.$, $r / R=0$, (a) $H=0$, (b) $H=644 \mathrm{~A} / \mathrm{m}$, (c) $H=1073 \mathrm{~A} / \mathrm{m}$, (d) $H=1502$ $\mathrm{A} / \mathrm{m}]$. 
(a)

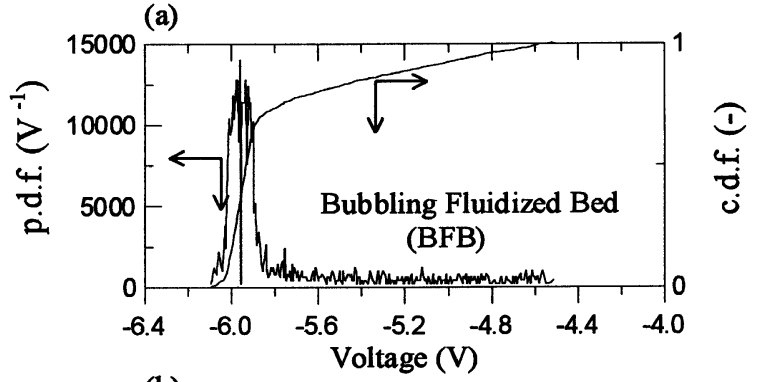

(b)

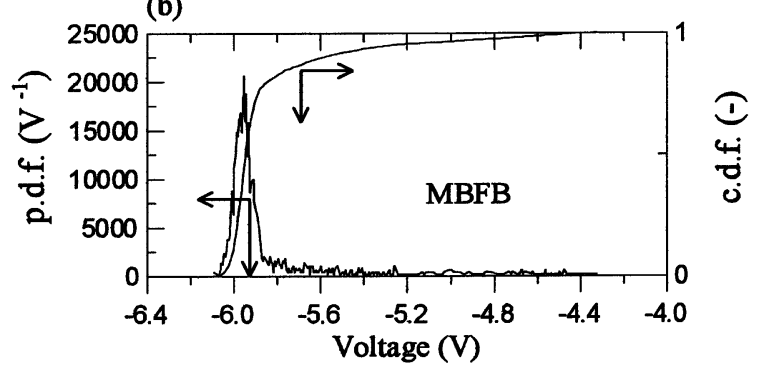

(c)

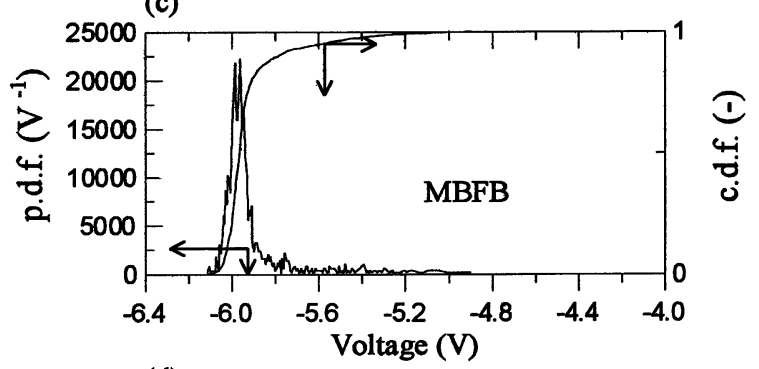

(d)

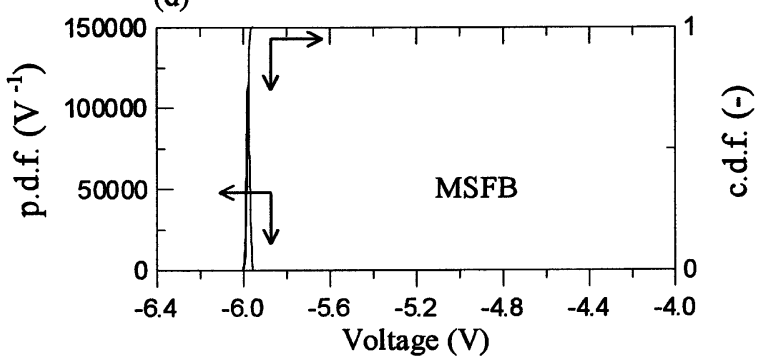

Fig. 10. Probability density and cumulative distribution functions of voidage signal at various magnetic field intensities. Higher voltage stands for larger voidage. $\left[U_{\mathrm{s}}=1.75 U_{\mathrm{mf}}, z / h_{\mathrm{s}}=0.878, r / R=0\right.$, (a) $H=0$, (b) $H=644 \mathrm{~A} / \mathrm{m}$, (c) $H=1073 \mathrm{~A} / \mathrm{m}$, (d) $H=1502 \mathrm{~A} / \mathrm{m}]$.

\subsection{Phase diagram of $M F B$}

The state of particle motion in an MFB is shown in Fig. 12. It could be subdivided into three basic operating regimes. $U_{\mathrm{mf}}$ was a constant that is not affected by the magnetic field intensity. $U_{\mathrm{e}}$ increased with increasing the intensity of magnetic field. The result was consistent with those in Ref. [19], ${ }^{2}$ Lee [32], Penchev and Hristov [33], Lee [34], Jovanovic and Jovanovic [30], and Hristov [35].

\footnotetext{
${ }^{2}$ This is cited as Filippov's work.
}

They reported that $U_{\mathrm{e}}$ generally increases with increasing the intensity of magnetic field. $U_{\mathrm{e}}$ slightly depends on the field intensity in an axial magnetic field and moderate magnetic properties of the particulate material used. However, any changes of the field topology causing a heterogeneous distribution of the field lines inside the working volume lead to an increase of $U_{\mathrm{e}}$. $U_{\mathrm{t}}$ increased with increasing magnetic field intensity.

When gas velocity was below $U_{\mathrm{e}}$, the drag force on the particles induced by the flow of gas was smaller than the effective weight of the particles in the system. The gas merely percolated through the void spaces between stationary particles. This was a fixed bed. With gas velocity beyond $U_{\mathrm{e}}$, the bed expanded but no gas bubbles were seen to be present, particles did not move about freely nor did they back mixing because magnetic field suppressed bubble formation. This was the MSFB. With a further increasing gas velocity, the pressure drop approached the bed weight per unit bed cross-sectional area in an MSFB. This was similar to that in a bubbling bed without applying magnetic field. When gas velocity was beyond $U_{t}$, the magnetic field could no longer suppress the bubble formation. Bubbles began to rise through the bed. This was the MBFB.

\subsection{Effect of gas velocity on particle concentration}

Fig. 13 shows the variation of solids fraction at the bed center with gas velocity. These curves show that there were three flow regimes under the influence of an external magnetic field. Each flow regime had its own distinctive concentration-velocity curve.

In Fig. 13, without applying magnetic field, the solids fraction initially remained constant at low gas velocity. The solids fraction began to decrease when gas velocity was equal to minimum fluidization velocity. The solids fraction decreased linearly when superficial gas velocity was beyond minimum fluidization velocity. When the gas velocity was decreased, the solids fraction increased sharply. The solids fraction became a constant when gas velocity was equal to minimum fluidization velocity. When gas velocity was smaller than minimum fluidization velocity, the solids fraction remained constant until the gas velocity decreased to zero. The bed is initially fluidized along $\mathrm{ABC}$ and then defluidized along CDE. Defluidization does not follow $\mathrm{AB}$, thus producing a structural hysteresis effect.

At same magnetic field intensity $(H=3003 \mathrm{~A} / \mathrm{m})$, the solids fraction initially remained constant at low gas velocity and began to decrease at $U_{\mathrm{e}}$. Then the solids fraction changed irregularly with increasing gas velocity because solid particles aligned repeatedly along the magnetic force lines. The solids fraction always changed irregularly with increasing gas velocity at different magnetic field intensity. The irregular change of voidage may be regarded as a character of MSFBs, which is different from the constant 


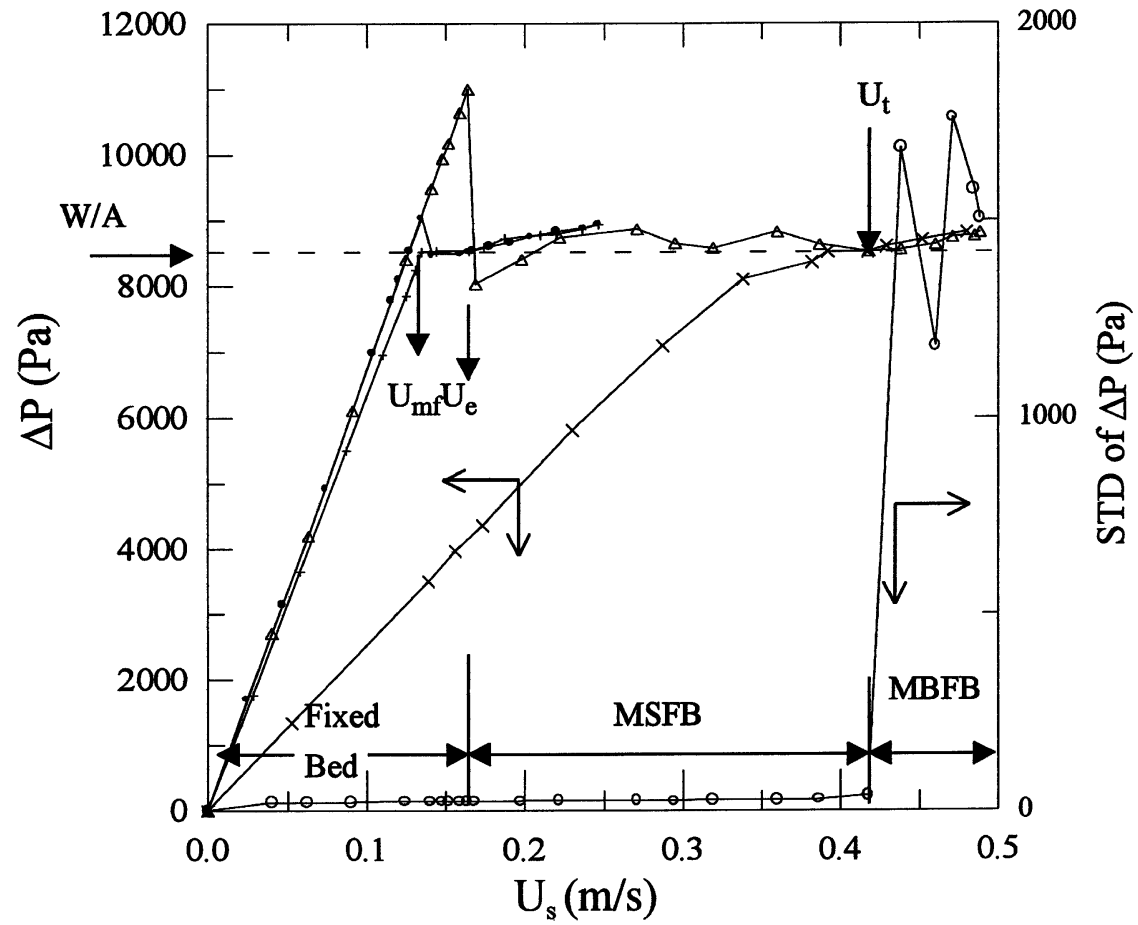

Fig. 11. Variation of bed pressure drop with gas velocity. $[H=0(\bullet,+), 3003(\Delta, \times) \mathrm{A} / \mathrm{m} ; \bullet, \Delta:$ increase velocity;,$+ \times:$ decrease velocity]

voidage of fixed bed. The solids fraction linearly decreased when gas velocity was beyond transition velocity. When the gas velocity was decreased, the solids fraction increased sharply. When gas velocity was smaller than transition velocity, the solids fraction increased continually with decrease in gas velocity. The solids fraction became a constant when gas velocity was equal to $U_{\mathrm{mf}}$. When gas velocity was smaller than $U_{\mathrm{mf}}$, the solids fraction remained same until the gas velocity decreased to zero. The bed is

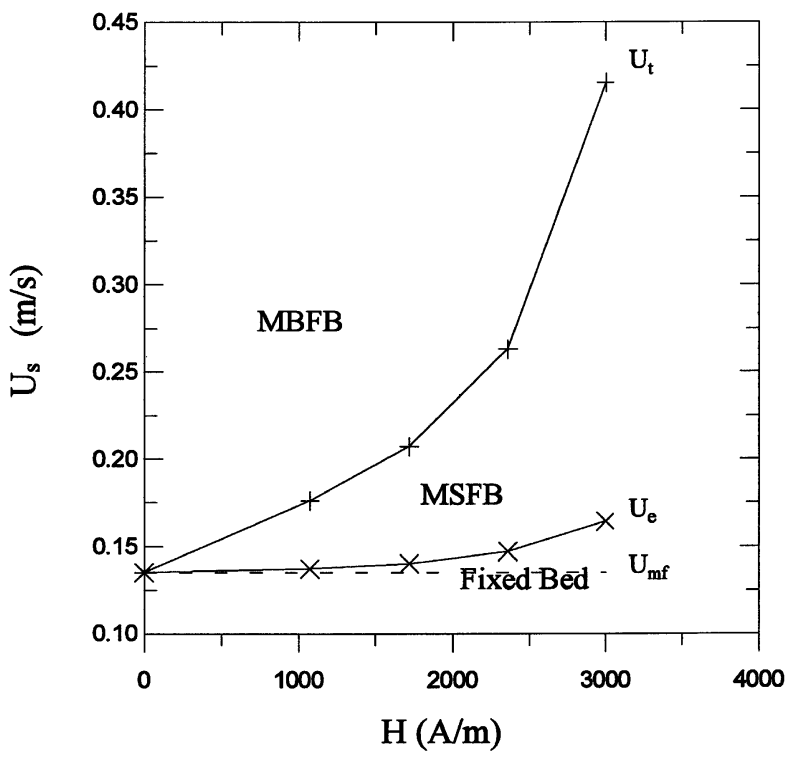

Fig. 12. Phase diagram of magnetically fluidized bed. initially fluidized along AFGH and then defluidized along HIJ. Defluidization does not follow AFG, thus producing a structural hysteresis effect. As the magnetic field intensity is increased, the points $\mathrm{F}, \mathrm{G}, \mathrm{H}$, and I can be moved to the right, thus enhancing hysteresis effect.

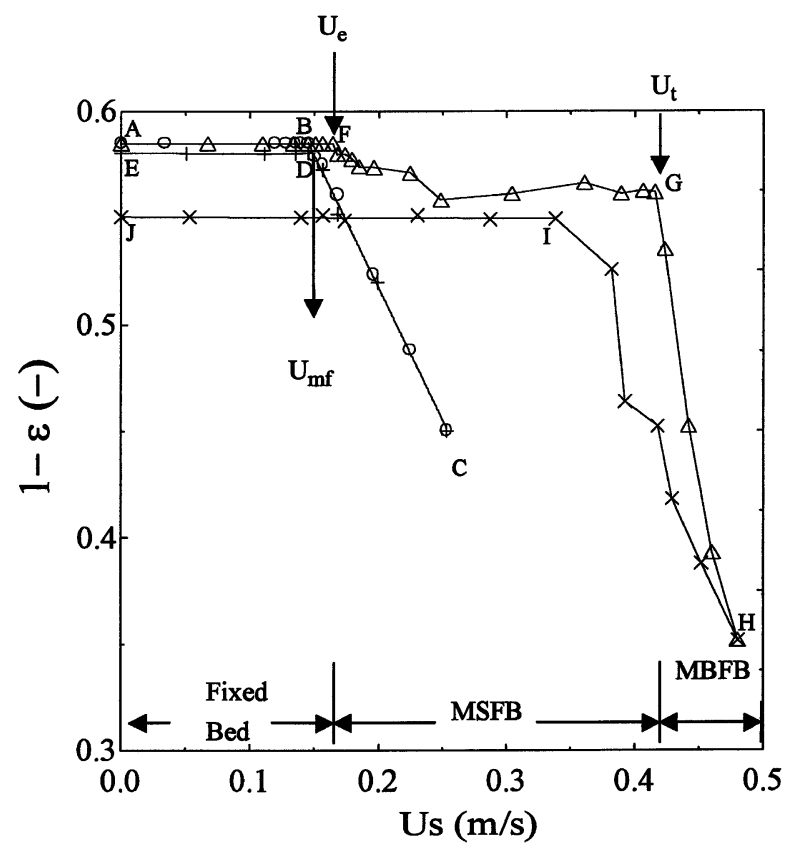

Fig. 13. Effect of gas velocity on solids fraction at the bed center. $\left[z / h_{\mathrm{s}}=0.878, H=0(\mathrm{O},+), 3003(\Delta, \times) \mathrm{A} / \mathrm{m} ; \bigcirc, \Delta:\right.$ increase velocity;,$+ \times$ : decrease velocity]. 


\subsection{Radial particle concentration profiles}

Solids fraction profile at various distances from the axis of bed column, distances from the distributor, gas velocities, and with and without applying magnetic field is shown in Figs. 14-16.

In Fig. 14(a)-(b), without applying magnetic field, and at $U_{\mathrm{s}} / U_{\mathrm{mf}}=1.28$ and 1.42 (bubbling regime), the solids fraction increased gradually with increasing distance from the axis of bed column at different distances from the distributor $\left(z / h_{\mathrm{s}}=0.312\right.$ and 0.878). In Fig. 14(a)-(d), at same distance from the axis of bed column, the solids fraction at $z / h_{\mathrm{s}}=0.312$ was larger than that at $z / h_{\mathrm{s}}=$ 0.878 . This result indicates the bubble at low $z / h_{\mathrm{s}}$ is smaller than that at high $z / h_{\mathrm{s}}$. At same distance from the axis of bed column, the difference of solids fraction be-

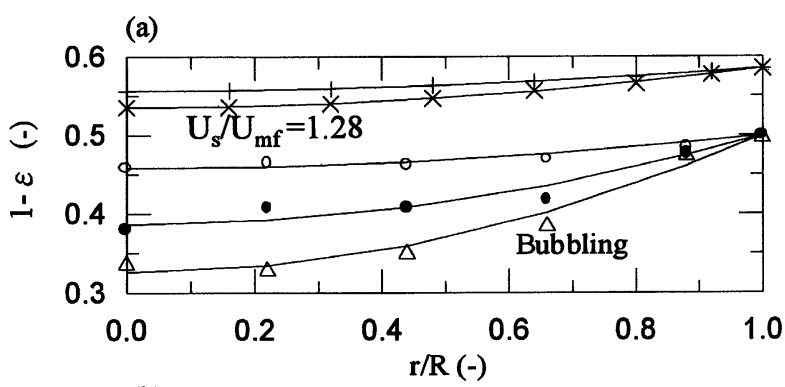

(b)

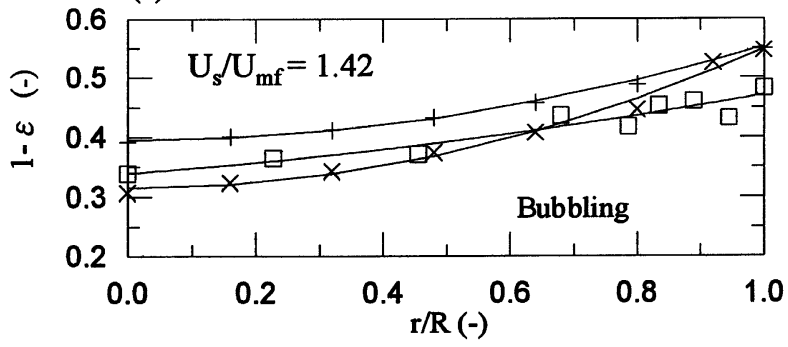

(c)

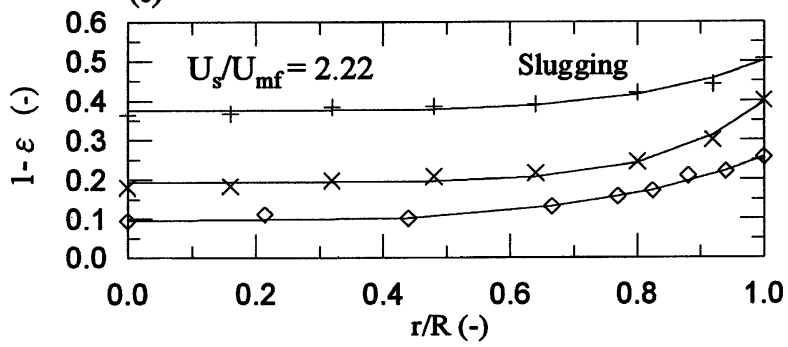

(d)

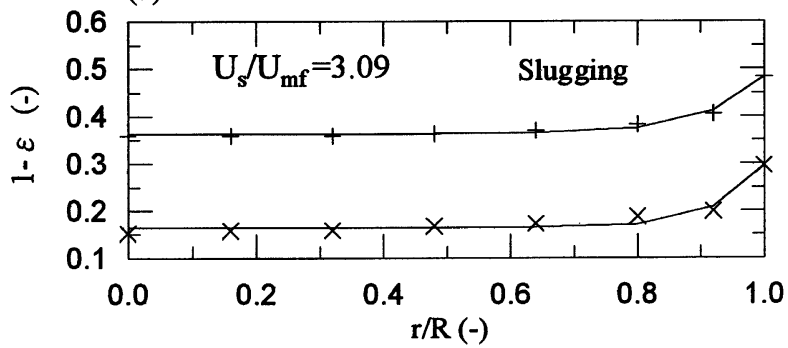

Fig. 14. Radial solids fraction profiles at various gas velocities without applying magnetic field. $\left[z / h_{\mathrm{s}}=0.312(+), 0.878(\times) ; \bigcirc, \bigcirc, \Delta:\right.$ Hao et al. [36]; $\square, \diamond:$ Zhang et al. [24]]. tween $v=0.312$ and $z / h_{\mathrm{s}}=0.878$ increased with increasing gas velocity.

In Fig. 14(a), the solids fraction profiles at both $z / h_{\mathrm{s}}=$ 0.312 and 0.878 were parabolic. Hao et al. [36] reported a similar result. In Fig. 14(b), the solids fraction profiles were still parabolic at both $z / h_{\mathrm{s}}=0.312$ and 0.878 . Zhang et al. [24] reported a similar result. In Fig. 14(c), without applying magnetic field, and at $U_{\mathrm{s}} / U_{\mathrm{mf}}=2.22$ (slugging regime), the solids fraction profile was flat for small $r / R$ but steep for large $r / R$. This kind of curve is known as 'flat-steep curve'. The demarcation point between flat and steep $\left[(r / R)_{\text {de }}\right]$ is 0.64 . Zhang et al. [24] reported a similar result. In Fig. 14(d), without applying magnetic field, and at $U_{\mathrm{s}} / U_{\mathrm{mf}}=3.09$ (slugging regime), the solids fraction profile was also a flat-steep curve with $(r / R)_{\mathrm{de}}=0.8$. The solids fraction profile at both $U_{\mathrm{s}} / U_{\mathrm{mf}}=2.22$ and 3.09 was distinctly flatter than that at both $U_{\mathrm{s}} / U_{\mathrm{mf}}=1.28$ and 1.42 . The greater the gas velocity, the flatter is the radial voidage profile. It suggests that the mechanisms of gassolid behavior in bubbling and slugging are different. At same distance from the distributor, the solids fraction at $U_{\mathrm{s}} / U_{\mathrm{mf}}=2.22$ was smaller than that at $U_{\mathrm{s}} / U_{\mathrm{mf}}=1.42$ because the bubble in the slugging regime is larger than that in the bubbling regime.

In Fig. 15(a), with applying magnetic field $(H=858$ $\mathrm{A} / \mathrm{m})$, and at $U_{\mathrm{s}} / U_{\mathrm{mf}}=1.42$, the radial solids fraction profiles were parabolic at both $z / h_{\mathrm{s}}=0.312$ and 0.878 . At the same distance from the axis of bed column and distance from the distributor, the solids fraction at $H=858$ $\mathrm{A} / \mathrm{m}$ was larger than that without applying magnetic field (Fig. 14(a)), because the magnetic field suppresses bubble formation.

In Fig. 15(b), with applying magnetic field $(H=858$ $\mathrm{A} / \mathrm{m})$, and at $U_{\mathrm{s}} / U_{\mathrm{mf}}=2.22$, the radial solids fraction profiles at different $z / h_{\mathrm{s}}$ were flat-steep curves with $(r / R)_{\mathrm{de}}=0.32$.

In Fig. 15(c), with applying magnetic field $(H=858$ $\mathrm{A} / \mathrm{m})$, and at $U_{\mathrm{s}} / U_{\mathrm{mf}}=3.09$, the radial solids fraction profiles at different $z / h_{\mathrm{s}}$ were flat-steep curves with $(r / R)_{\mathrm{de}}=0.48$. The greater the gas velocity, the flatter is the radial voidage profile. The result with applying magnetic field was similar to that without applying magnetic field.

In Fig. 16(a), with applying magnetic field $(H=1716$ $\mathrm{A} / \mathrm{m})$, and at $U_{\mathrm{s}} / U_{\mathrm{mf}}=2.22$, the radial solids fraction profiles were parabolic at different $z / h_{\mathrm{s}}$. In Fig. 16(b), with applying magnetic field $(H=1716 \mathrm{~A} / \mathrm{m})$, and at $U_{\mathrm{s}} / U_{\mathrm{mf}}=3.09$, the solids fraction profile was almost a parabola at $z / h_{\mathrm{s}}=0.312$ but a flat-steep curve with $(r / R)_{\mathrm{de}}=0.32$ at $z / h_{\mathrm{s}}=0.878$.

The following equation can correlate the experimental data of solids fraction well:

$$
(1-\varepsilon)=(1-\varepsilon)_{\mathrm{c}}+\left[(1-\varepsilon)_{\mathrm{w}}-(1-\varepsilon)_{\mathrm{c}}\right](r / R)^{B},
$$


(a)

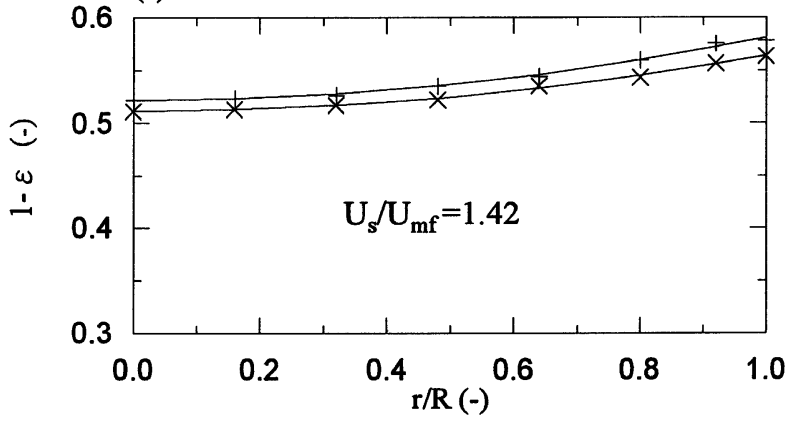

(b)

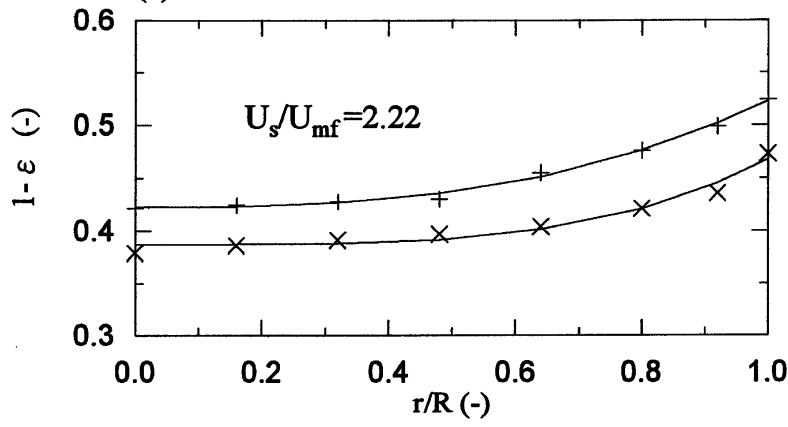

(c)

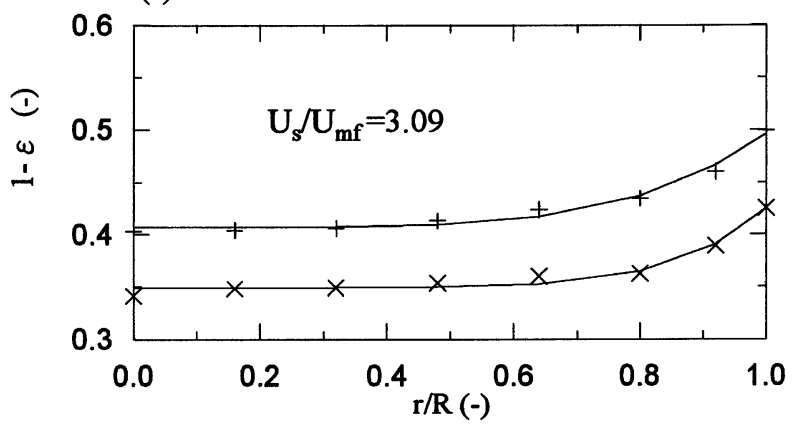

Fig. 15. Radial solids fraction profiles at various gas velocities at $H=858 \mathrm{~A} / \mathrm{m} .\left(+: z / h_{\mathrm{s}}=0.312, \times: z / h_{\mathrm{s}}=0.878\right)$.

where $(1-\varepsilon),(1-\varepsilon)_{\mathrm{c}}$ and $(1-\varepsilon)_{\mathrm{w}}$ represent the solids fraction at arbitrary position in the bed, at the bed center and on the bed wall; $B,(1-\varepsilon)_{\mathrm{c}}$ and $(1-\varepsilon)_{\mathrm{w}}$ are the function of air velocity, distance from the distributor and magnetic field intensity. In order to estimate $(1-\varepsilon)$ by least-squares approximation, we rewrote Eq. (9) in terms of three coefficients $(C, D$ and $E$ ) as follows:

$(1-\varepsilon)=C+[D-C](r / R)^{E}$.

The experimental data from each of the radial solids fraction profiles in this work were used separately to fit an equation of the form Eq. $\left(9^{\prime}\right)$. Eight fitted values of $(1-\varepsilon)$ at eight $r / R$ positions and three fitted values of coefficients $(C, D$ and $E)$ were given for each fit. These eleven fitted values were individual for each fit. The relations of $(1-\varepsilon)$ with $\mathrm{C}$ and $\mathrm{D}$ were as follows:

at $r / R=0$ (bed center), $(1-\varepsilon)=C$,

hence $C=(1-\varepsilon)_{\mathrm{c}}$,

at $r / R=1($ bed wall $),(1-\varepsilon)=D$,

hence $D=(1-\varepsilon)_{\mathrm{w}}$.
The fitted values of solids fraction by Eq. $\left(9^{\prime}\right)$ for the 192 experimental data in this work were only $2 \%$ standard deviation (S. D.), thus Eq. ( $\left.9^{\prime}\right)$ could be written as the form of Eq. (9). The standard deviation of the fitted values from the experimental values was defined as follows:

S.D. $=\sqrt{\frac{\sum\left[\left(\frac{\text { calculating value }- \text { experimental value }}{\text { experimental value }}\right) \times 100 \%\right]^{2}}{\text { the number of data }-1}}(\%)$.

The fitted values of solids fraction by Eq. $\left(9^{\prime}\right)$ for the 18 experimental data of Hao et al. [32] (Fig. 14(a)) was also only $2 \%$ S.D. The fitted values of solids fraction by Eq. $\left(9^{\prime}\right)$ for the 18 experimental data of Zhang et al. [25] (Fig. 14(b) and (c)) are 4\% and 5\% S.D. respectively.

The value of $(1-\varepsilon)_{c}$ can be calculated by the following equation:

$$
\begin{aligned}
(1-\varepsilon)_{\mathrm{c}}= & (1-\varepsilon)_{\mathrm{co}} \times 10^{-H}+\left\{\left(U_{\mathrm{s}} / U_{\mathrm{mf}}\right)^{1.5}\right. \\
& \left./\left[5.4609\left(U_{\mathrm{s}} / U_{\mathrm{mf}}\right)-4.5987\right]\right\} \\
& \times\left\{\exp \left[-0.0315\left(U_{\mathrm{s}} / U_{\mathrm{mf}}\right)^{2}\left(z / h_{\mathrm{s}}\right)\right]\right\} \\
& \times\left[H^{1.14} /(2.5738 H+1)\right],
\end{aligned}
$$

where $(1-\varepsilon)_{\mathrm{co}}=0.5627 \exp \left[-0.4525\left(U_{\mathrm{s}} / U_{\mathrm{mf}}-1.28\right)^{0.11}\right.$ $\left.-1.1451\left(U_{\mathrm{s}} / U_{\mathrm{mf}}-1.27\right)^{0.5}\left(z / h_{\mathrm{s}}-0.3122\right)\right]$ is the solids fraction at the bed center without applying magnetic field. Comparison of solids fraction at the bed center calculated by Eq. (11) with experimental data is shown in Fig. 17.

(a)

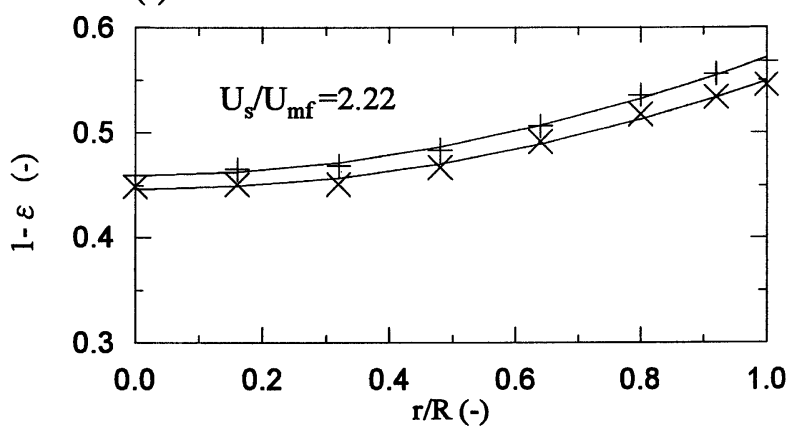

(b)

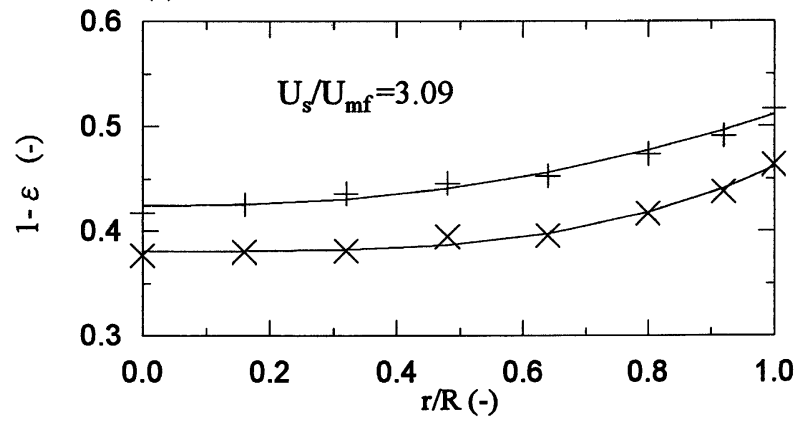

Fig. 16. Radial solids fraction profiles at various gas velocities at $H=1716 \mathrm{~A} / \mathrm{m} .\left(+: z / h_{\mathrm{s}}=0.312, \times: z / h_{\mathrm{s}}=0.878\right)$. 


\begin{tabular}{|c|c|c|c|}
\hline $\begin{array}{c}\text { Experi- } \\
\text { mental } \\
\text { data }\end{array}$ & $\begin{array}{c}\text { Results } \\
\text { calculate } \\
\text { by Eq. (11) }\end{array}$ & $\mathrm{z} / \mathrm{h}_{\mathrm{s}}(-)$ & $\mathrm{H}(\mathrm{A} / \mathrm{m})$ \\
\hline+ & - & 0.3122 & 0 \\
\hline 0 & - & 0.8783 & 0 \\
\hline$\triangle$ & - & 0.3122 & 858 \\
\hline$\bullet$ & - & 0.8783 & 858 \\
\hline$\Delta$ & - & 0.3122 & 1716 \\
\hline$\times$ & - & 0.8783 & 1716 \\
\hline
\end{tabular}

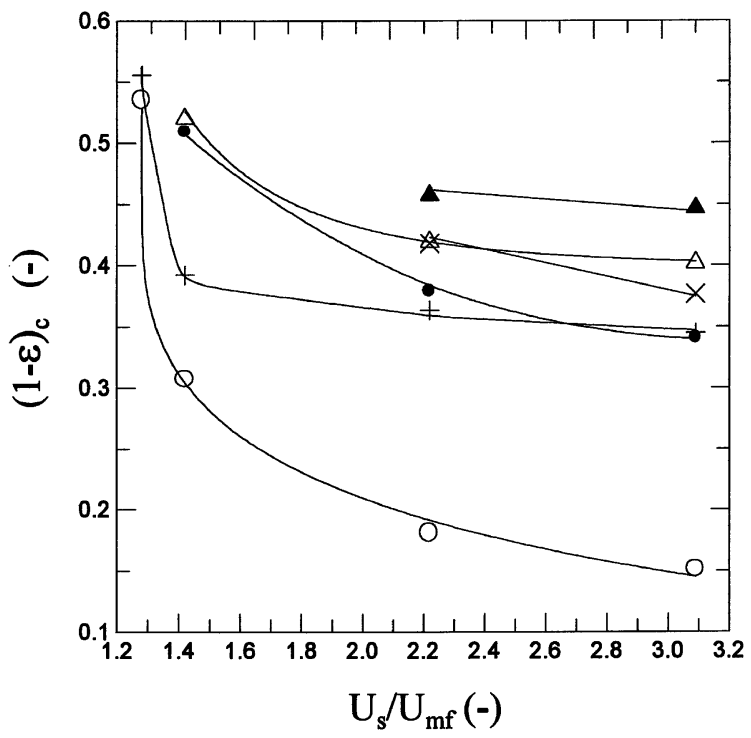

Fig. 17. Comparison of solids fraction at the bed center calculated by Eq. (11) with experimental data.

The fitted values of solids fraction by this equation were only $1.9 \%$ S.D.

The value of $(1-\varepsilon)_{\mathrm{w}}$ can be calculated by the following equation:

$$
\begin{aligned}
(1-\varepsilon)_{\mathrm{w}}= & (1-\varepsilon)_{\mathrm{wo}} \times 10^{-H}+\left\{\left(U_{\mathrm{s}} / U_{\mathrm{mf}}\right)^{1.3}\right. \\
& \left./\left[3.1334\left(U_{\mathrm{s}} / U_{\mathrm{mf}}\right)-1.783\right]\right\} \\
& \times\left\{\exp \left[-0.0309\left(U_{\mathrm{s}} / U_{\mathrm{mf}}\right)^{2}\left(z / h_{\mathrm{s}}\right)\right]\right\} \\
& \times\left[H^{1.12} /(2.2459 H+1)\right],
\end{aligned}
$$

where $(1-\varepsilon)_{\text {wo }}=0.5849 \exp \left[-0.1481\left(U_{\mathrm{s}} / U_{\mathrm{mf}}-\right.\right.$ $\left.1.28)^{0.42}-0.432\left(U_{\mathrm{s}} / U_{\mathrm{mf}}-1.28\right)^{1.2}\left(z / h_{\mathrm{s}}-0.3122\right)\right]$ is the solids fraction at the bed wall without applying magnetic field.

Comparison of solids fraction on the bed wall calculated by Eq. (12) with experimental data is shown in Fig. 18. The fitted values of solids fraction by this equation were only $2.2 \%$ S.D. The value of $B$ can be calculated by the following equation:

$$
\begin{aligned}
B= & B_{\mathrm{o}}+\left\{0.2003\left(U_{\mathrm{s}} / U_{\mathrm{mf}}\right)^{0.2}-0.1101\left(U_{\mathrm{s}} / U_{\mathrm{mf}}\right)^{1.8}\right. \\
& \left.\times \exp \left[0.1247\left(z / h_{\mathrm{s}}\right)\right]\right\} \times\left[H^{1.6} /(6.1751 H+1)\right],
\end{aligned}
$$

where $\quad B_{\mathrm{o}}=\left[0.3772 /\left(U_{\mathrm{s}} / U_{\mathrm{mf}}-1\right)+3.7718\left(U_{\mathrm{s}} / U_{\mathrm{mf}}-\right.\right.$ $\left.1)^{1.4}\right] \exp \left\{\left[0.4282-0.7909\left(U_{\mathrm{s}} / U_{\mathrm{mf}}\right)^{-2.5}\right]\left(z / h_{\mathrm{s}}-0.3112\right)\right\}$ is the $B$ value without applying magnetic field. Comparison of $B$ value calculated by Eq. (13) with that calculated by Eq. $\left(9^{\prime}\right)$ is shown in Fig. 19. The fitted values of $B$ by this equation were only $3.8 \%$ S.D.

When the gas velocity was decreased or the magnetic field intensity was increased, the value of $B$ approaches 2 , the solids fraction profile is parabolic. When the value of $B$ becomes large, the parabola becomes a flat-steep curve. The greater the value of $B$, the flatter is the radial solids fraction profiles.

To compare radial solids fraction profiles under different operating conditions without applying magnetic field, the reduced radial solids fraction, i.e. the ratio of local solids fraction to the cross-sectional average solids fraction, is plotted against the radial position, as shown in Fig. 20. In this figure, the data measured by Zhang et al. [24] are also given. No matter how the apparatus is different, the reduced radial solids fraction has same tendency: (1) There is one or two intersections between the curve of the reduced radial solids fraction profile in the bubbling regime and that in the slugging regime. (2) The radial solids fraction profiles in the central bed region in the slugging bed was distinctly flatter than that in the bubbling bed, but

\begin{tabular}{|c|c|c|c|}
\hline $\begin{array}{c}\text { Experi- } \\
\text { mental } \\
\text { data }\end{array}$ & $\begin{array}{c}\text { Results } \\
\text { calculated } \\
\text { by Eq. (12) }\end{array}$ & $z / \mathrm{h}_{\mathrm{s}}(-)$ & $\mathrm{H}(\mathrm{A} / \mathrm{m})$ \\
\hline+ & - & 0.3122 & 0 \\
\hline 0 & - & 0.8783 & 0 \\
\hline$\triangle$ & - & 0.3122 & 858 \\
\hline$\bullet$ & - & 0.8783 & 858 \\
\hline$\Delta$ & - & 0.3122 & 1716 \\
\hline$\times$ & - & 0.8783 & 1716 \\
\hline
\end{tabular}

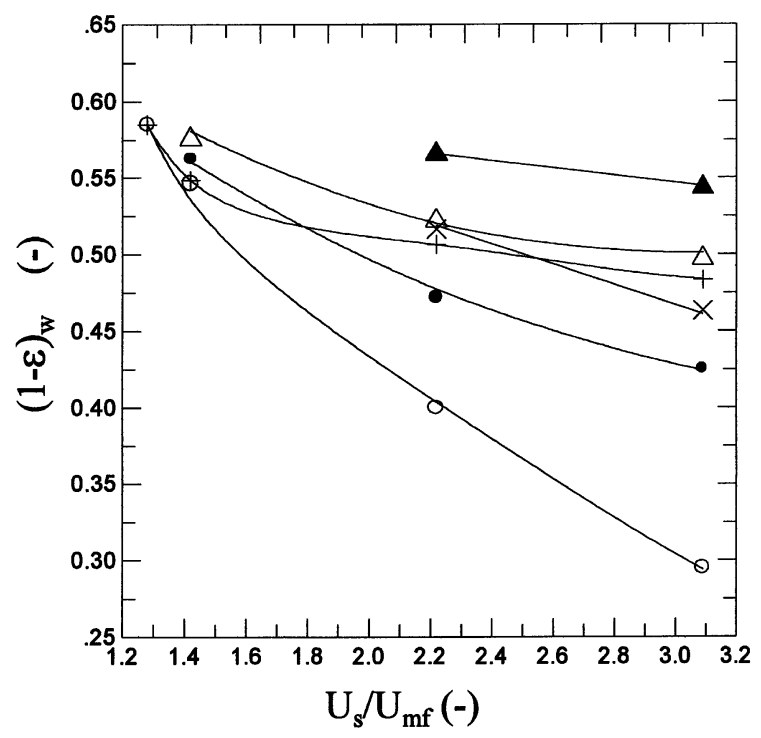

Fig. 18. Comparison of solids fraction on the bed wall calculated by Eq. (12) with experimental data. 


\begin{tabular}{|c|c|c|}
\hline Key & $\mathrm{z} / \mathrm{h}_{\mathrm{s}}(-)$ & $\mathrm{H}(\mathrm{A} / \mathrm{m})$ \\
\hline+ & 0.3122 & 0 \\
\hline$\circ$ & 0.8783 & 0 \\
\hline$\triangle$ & 0.3122 & 858 \\
\hline$\bullet$ & 0.8783 & 858 \\
\hline$\Delta$ & 0.3122 & 1716 \\
\hline$X$ & 0.8783 & 1716 \\
\hline
\end{tabular}

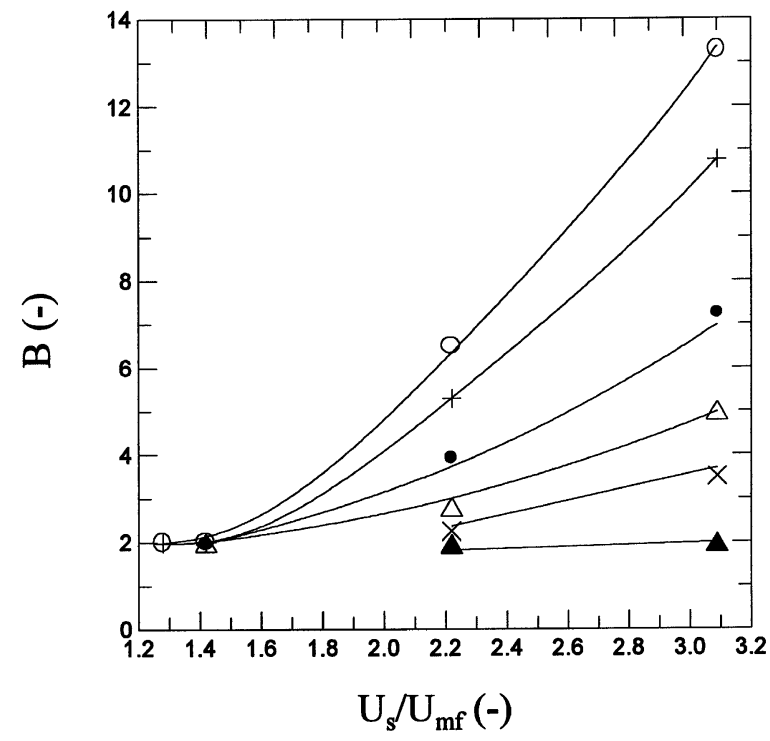

Fig. 19. Comparison of parameter B value in Eq. (13) calculated by Eq (13) with that calculated by Eq. $\left(9^{\prime}\right)$.

that near the bed wall in the slugging bed was steeper than that in the bubbling bed.

\subsection{Axial particle concentration profiles}

Axial solids fraction profiles without or with applying magnetic field at $U_{\mathrm{s}} / U_{\mathrm{mf}}=3.09$ is shown in Fig. 21.

In Fig. 21(a)-(c), the solids fraction decreased with increasing distance from the distributor showed that the bubble size in a fluidized bed increases with increasing distance from the distributor. At same distance from the distributor, the solids fraction at $H=858 \mathrm{~A} / \mathrm{m}$ is larger than that without applying magnetic field, and the solids fraction at $H=1716 \mathrm{~A} / \mathrm{m}$ is larger than that at $H=858$ $\mathrm{A} / \mathrm{m}$, because the bubble is smaller at higher magnetic field intensity.

The difference of solids fraction between the bed center and the bed wall was generally lower than that between the bed bottom and the bed top whether the magnetic field was applied to the bed or not.

\subsection{Effect of magnetic field intensity on particle concen- tration}

Solids fraction profile at various distances from the axis of bed column, at $z / h_{\mathrm{s}}=0.878$, at various gas velocities, and without or with applying magnetic field is shown in Fig. 22.

In Fig. 22(a), without applying magnetic field, the solids fraction profile was a parabola in the bubbling regime. This is similar to that reported by Zhang et al. [24]. In Fig. 22(b) and (c), without applying magnetic field, and in the slugging regime, the solids fraction profiles were flat-steep curves. This is also similar to that reported by Zhang et al. [24]. At same distance from the axis of bed column and distance from the distributor, the solids fraction at $H=1716 \mathrm{~A} / \mathrm{m}$ was larger than that at $H=858$ $\mathrm{A} / \mathrm{m}$. It suggests that the more magnetic field intensity, the more is the ability of suppressing bubble formation.

In Fig. 22(b) and (c), with applying magnetic field, and when magnetic field intensity was increased gradually, particles arranged along the magnetic force lines to give an orderly structure to the bed. Thus, particle concentration increased, the solids fraction profile changed gradually from a flat-steep curve into a parabola. When magnetic field intensity was increased again, bubbles disappeared, particle concentration further increased, and the solids fraction profile was a horizon. This means that the solids fraction is unchanged at a constant gas velocity in an MSFB.

\begin{tabular}{|c|c|c|c|c|c|}
\hline \multirow{2}{*}{ Authors } & Key & Regime & Particle & $\mathrm{U}_{\mathrm{s}}(\mathrm{m} / \mathrm{s})$ & $1-\bar{\varepsilon}$ \\
\hline \multirow{3}{*}{$\begin{array}{c}\text { Zhang } \\
\text { et al. }\end{array}$} & $x--$ & Bubbling & Hollow glass beads & 0.13 & 0.428 \\
\cline { 2 - 6 } & $\Delta--$ & Bubbling & Alumina & 0.15 & 0.341 \\
\cline { 2 - 6 } & $0--$ & Slugging & Alumina & 0.52 & 0.164 \\
\hline \multirow{4}{*}{ This work } & +- & Bubbling & Iron & 0.17 & 0.566 \\
\cline { 2 - 6 } & $\Delta-$ & Bubbling & Iron & 0.19 & 0.450 \\
\cline { 2 - 6 } & $\bullet-$ & Slugging & Iron & 0.30 & 0.265 \\
\hline
\end{tabular}

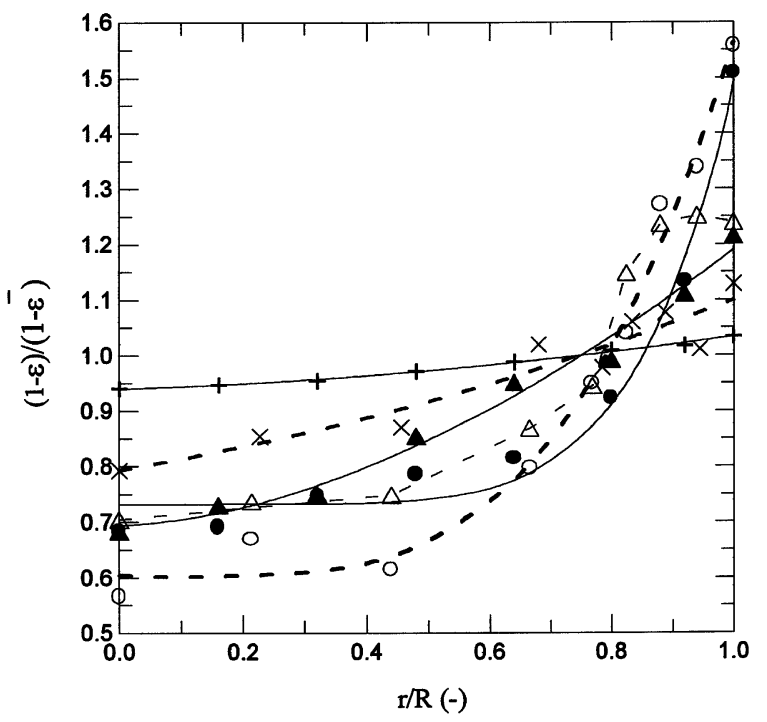

Fig. 20. Normalized radial solids fraction profiles in different regimes. 


\begin{tabular}{|l|l|l|l|l|l|l|l|l|}
\hline $\mathrm{r} / \mathbf{R}$ & 0 & 0.16 & 0.32 & 0.48 & 0.64 & 0.8 & 0.92 & 1 \\
\hline Symbol & + & 0 & $\square$ & 0 & $\bullet$ & $\Delta$ & $\nabla$ & $\times$ \\
\hline
\end{tabular}

(a)

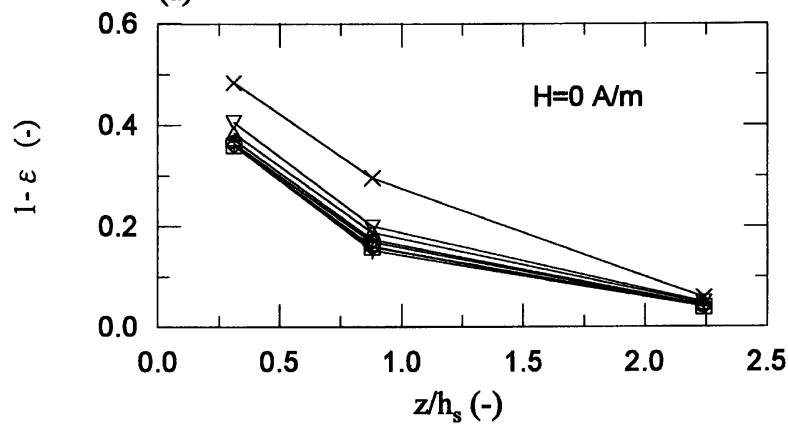

(b)

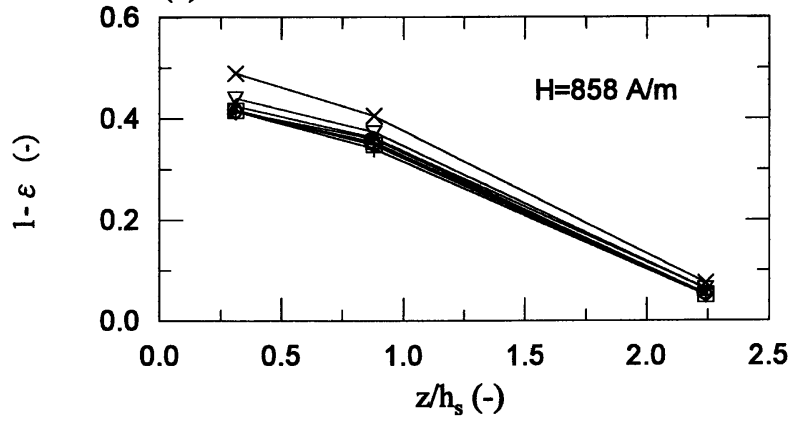

(c)

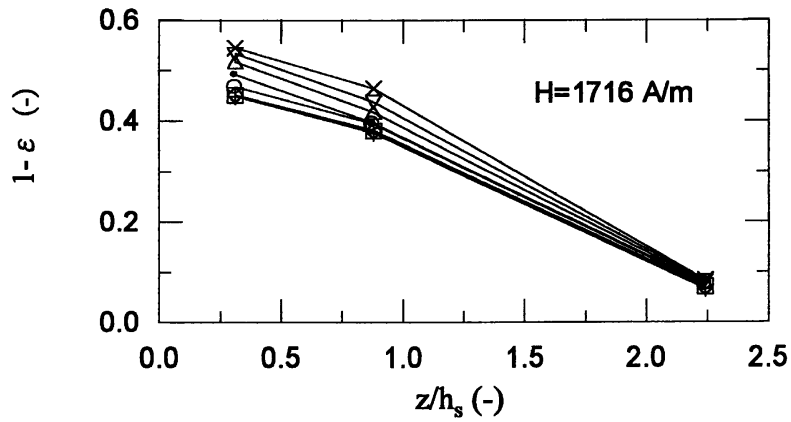

Fig. 21. Axial solids fraction profiles at various magnetic field intensities at $U_{\mathrm{s}} / U_{\mathrm{mf}}=3.09$.

\subsection{The difference between fixed beds and MSFBs}

As Fig. 11 shows, at same magnetic field intensity $(H=3003 \mathrm{~A} / \mathrm{m})$, the bed pressure drop in a fixed bed increased linearly with increasing gas velocity but that in an MSFB remained almost constant at the bed weight per unit bed cross-sectional area.

In Fig. 13, at same magnetic field intensity $(H=3003$ $\mathrm{A} / \mathrm{m}$ ), the solids fraction was constant in a fixed bed but irregular in an MSFB. Because the drag force of gas acting on particles was small in a fixed bed, the gas merely percolates through the void spaces between stationary particles. Thus, it leads to a constant solids fraction in a fixed bed. The drag force continuously increased with increasing gas velocity, though magnetic force suppressed bubble formation in an MSFB, particles aligned repeatedly to reach new force balance when gas velocity was increased.
Thus, it leads to the irregular change of solids fraction in an MSFB. The solids fraction in an MSFB was smaller than that in fixed bed because the expansion of bed increased the distance among particles.

The above unique characteristics of MSFBs compared to fixed beds can advantage to remove particulates from gases. This is similar to that reported by Cohen and Tien [4]. They studied aerosol filtration and reported both fixed beds and MSFBs provided high collection efficiencies. When aerosols were collected, the pressure drop increased within a fixed bed, but remained constant within an MSFB because the large porosities in an MSFB allowed the collection of aerosols without significantly decreasing the void volume.

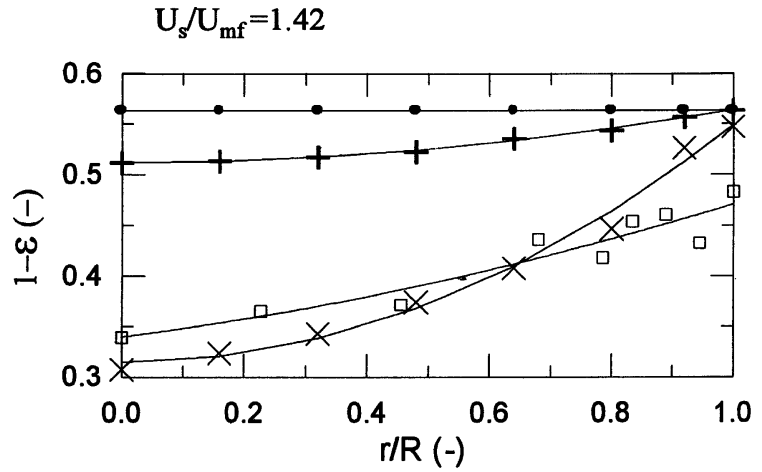

(a)

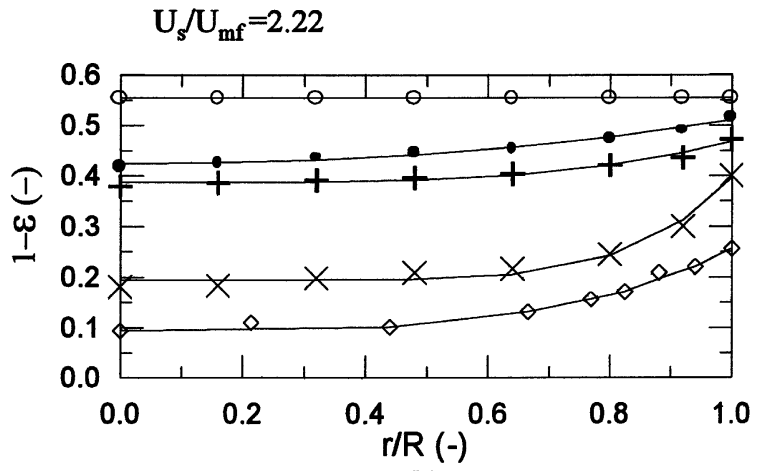

(b)

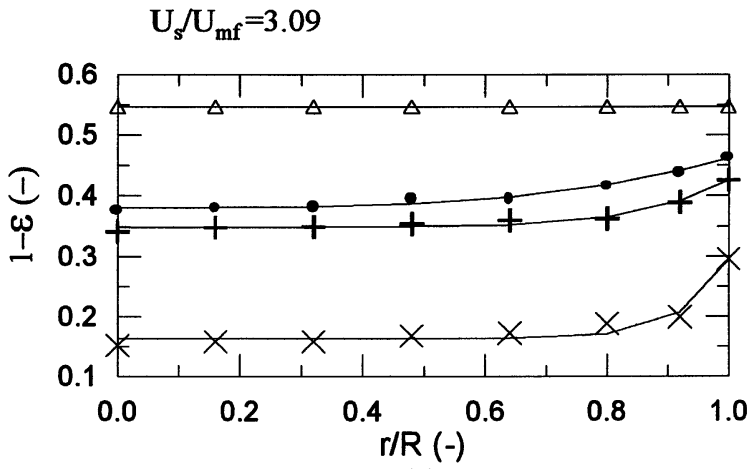

(c)

Fig. 22. Effect of magnetic field intensity on radial solids fraction profiles. $\left[z / h_{\mathrm{s}}=0.878 ; H=0(\times), 858(+), 1716(\bigcirc), 2574(\bigcirc)\right.$, $3432(\Delta) \mathrm{A} / \mathrm{m}$; $\square$ : particle: hollow glass beads, $\diamond$ : particle: alumina, Zhang et al. [24]]. 
As shown in Figs. 11 and 13, a fixed bed existed only in a narrow range of gas velocity. However, an MSFB could exist over a wide range of gas velocity; the range extended further as the applied field intensity increased. Therefore, an MSFB could be applied in specific situations such as particle separation and ammonia synthesis. Similarly, Sikavitsas et al. [15] described that an MSFB improves intraparticle mass transfer properties. The pressure drop creates a limitation for the allowable particle size in a fixed bed, but this limit is removed and much smaller particle sizes are allowed within an MSFB, thus improves the separations with strong diffusion limitations.

Zrunchev and Popova [16] also presented a similar result. Their experimental result showed that an MSFB are applicable at relatively high linear rates that are higher than $U_{\mathrm{mf}}$. This enhances the rate of mass transfer processes and the total rate of the heterogeneous process, thus allow ammonia synthesis at low pressures.

\subsection{The difference between MSFBs and MBFBs}

As Fig. 11 shows, at same magnetic field intensity $(H=3003 \mathrm{~A} / \mathrm{m})$, the bed pressure drop remained almost constant at the bed weight per unit bed cross-sectional area in both MSFB and MBFB.

In Fig. 13, at same magnetic field intensity $(H=3003$ $\mathrm{A} / \mathrm{m}$ ), the variation of solids fraction in an MSFB was irregular because solid particles aligned repeatedly along the magnetic force lines under the interaction of drag force, gravity force, magnetic force, friction force and interparticle forces. The solids fraction decreased sharply on the straight in an MBFB because bubbles increased the distance among particles.

As shown in Figs. 9 and 10, the greater the magnetic field intensity, the smaller was the size of bubbles and the fewer were the number of bubbles in an MBFB. Therefore, an MBFB could change the size and number of bubble by regulating the magnetic field intensity, thus changed the strength of contact mass and gave the optimum rates of the catalytic process. This is similar to the result of Zrunchev and Popova [16]. They reported that the magnetic stabilization facilitates controlling and eliminating the circulation and bubble formation in the beds. The magnetic stabilization allows the process to take peace at a considerably lower pressure due to the enhanced active surface area and the restriction of the diffusion-induced resistance in the particles.

\subsection{The difference between bubbling fluidized beds (BFBs) and MBFBs}

The difference between BFBs and MBFBs could be found from the following measurements: the wave forms and probability density function of voidage signal, pressure fluctuations, local solids fraction, and radial solids fraction profiles.

As shown in Fig. 9(a), (b) and (c), at same gas velocity, the peaks in an MBFB were smaller and fewer than those in a BFB, i.e. the bubbles in an MBFB were smaller and fewer than those in a BFB. The result suggests that magnetic force suppressed bubble formation.

In Fig. 10(a), (b) and (c), the probability density function of voidage signal in an MBFB was sharper than that in a BFB, i.e. the voidage profile in an MBFB was narrower than that in a BFB. It was possible that the greater particle concentration in an MBFB decreased the distribution range of bubbles.

As Fig. 11 shows, the pressure fluctuations in a BFB increased linearly with increasing gas velocity but those in an MBFB appeared suddenly and were more violent than those in a BFB. It could be that the drag force acting on the particles at higher gas velocity $\left(U_{\mathrm{t}}\right)$ was larger than that at lower gas velocity $\left(U_{\mathrm{e}}\right)$.

In Fig. 13, the solids fraction decreased linearly in both BFB and MBFB, but the straight in an MBFB was steeper than that in a BFB due to the greater gas velocity in an MBFB.

Figs. 14(a)-(b) and 15(a) show the radial solids fraction profiles were parabolic in both BFB and MBFB. However, the solids fraction at the same gas velocity in an MBFB was larger than that in a BFB, the collection efficiencies of an MBFB might be higher than that in a fixed bed. This is similar to that reported by Cohen and Tien [4]. They reported the unstable bed conditions (i.e. bubbling) resulted directly in the low collection efficiencies.

\subsection{Particle concentration in freeboard}

The radial solids fraction profiles in freeboard $\left(z / h_{\mathrm{s}}=\right.$ 2.24) at both $U_{\mathrm{s}} / U_{\mathrm{mf}}=3.09$ and 5.26, and without or with applying magnetic field is shown in Fig. 23.

(a)
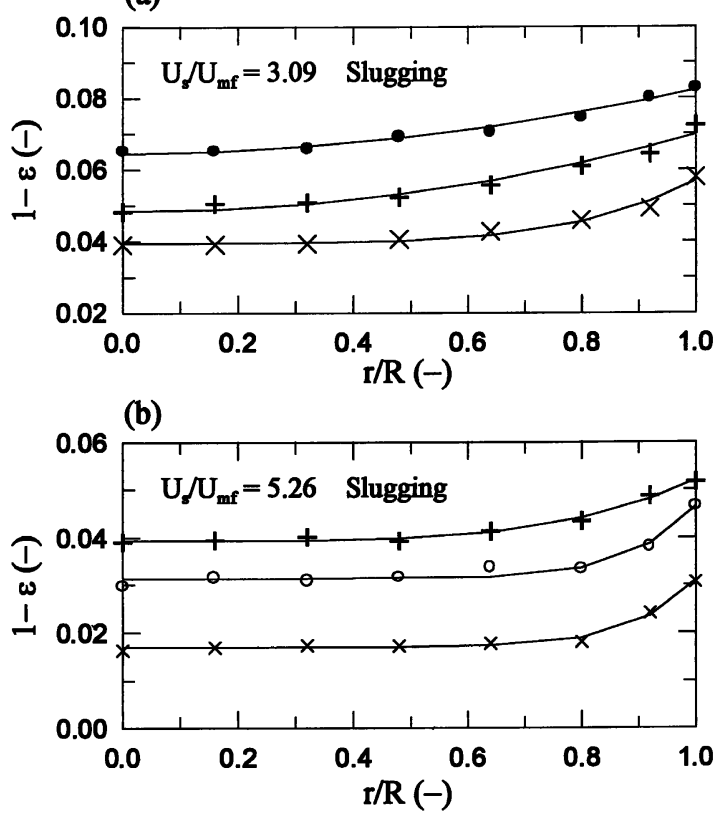

Fig. 23. Radial solids fraction profiles in freeboard. $\left[z / h_{\mathrm{s}}=2.24, H=0\right.$ $(\times), 429(\bigcirc), 858(+), 1716(\bigcirc) \mathrm{A} / \mathrm{m}]$. 


\begin{tabular}{|l|c|c|c|c|c|c|c|c|}
\hline $1-\varepsilon(-)$ & 0.05 & 0.10 & 0.15 & 0.2 & 0.25 & 0.30 & 0.35 & 0.40 \\
\hline Symbol & - & - & - & - & $\Xi$ & 0 & $\nabla$ & $\Delta$ \\
\hline
\end{tabular}

\begin{tabular}{|c|c|c|c|c|c|c|c|c|c|}
\hline $1-\varepsilon(-)$ & 0.45 & 0.50 & 0.51 & 0.52 & 0.53 & 0.54 & 0.55 & 0.56 & 0.5634 \\
\hline Symbol & $\Delta$ & $*$ & + & $\diamond$ & $\bullet$ & $\square$ & $\times$ & $\nabla$ & $\bullet$ \\
\hline
\end{tabular}

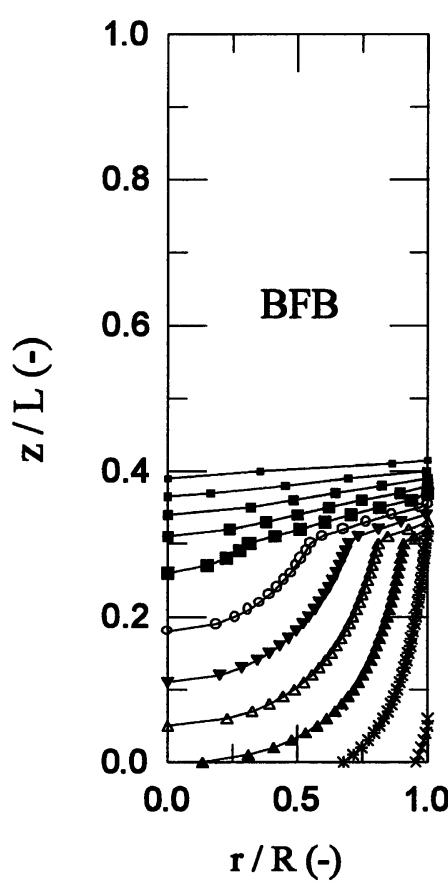

(a)

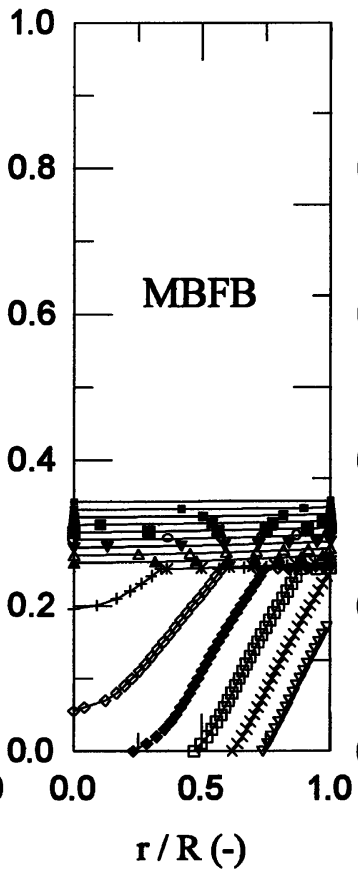

(b)

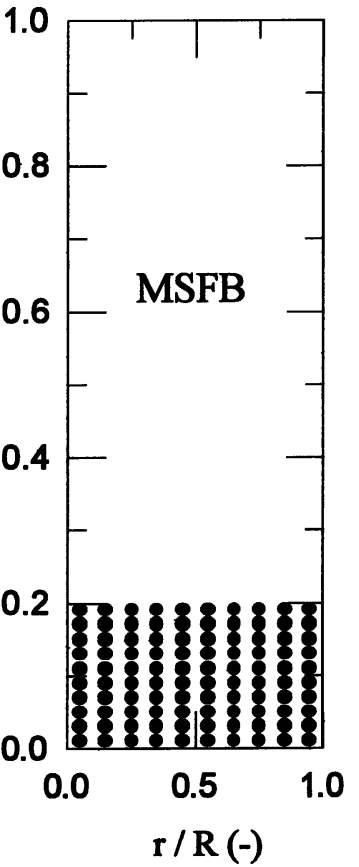

(c)

Fig. 24. Computed solids fraction profiles at various fluidized regimes. $\left[\mathrm{h}_{\mathrm{s}}=0.189 \mathrm{~m}, \mathrm{~L}=1 \mathrm{~m}, U_{\mathrm{s}} / U_{\mathrm{mf}}=1.42, H=\right.$ (a) 0 , (b) 858 , (c) $\left.1716 \mathrm{~A} / \mathrm{m}\right]$.

In Fig. 23(a), at $U_{\mathrm{s}} / U_{\mathrm{mf}}=3.09$ (slugging regime), without applying magnetic field, the solids fraction profile was a flat-steep curve. With applying magnetic field $(H=858$ or $1716 \mathrm{~A} / \mathrm{m}$ ), the curve became a parabola.

In Fig. 23(b), at $U_{\mathrm{s}} / U_{\mathrm{mf}}=5.26$ (slugging regime), the radial solids fraction profiles were flat-steep curves whether the magnetic field was applied to the bed or not.

The greater the gas velocity or the less magnetic field intensity, the flatter are the radial solids fraction profiles.

\subsection{Computed particle concentration distributions at var- ious fluidized regimes}

Fig. 24 shows the computed local solids fraction at $U_{\mathrm{s}} / U_{\mathrm{mf}}=1.42$ in a BFB, an MBFB and an MSFB by Eqs. (9)-(13) as a function of $z / L$ and $r / R$.

Substitution of $U_{\mathrm{s}} / U_{\mathrm{mf}}=1.42$ into Eqs. (11)-(13) and (9) gave local solids fraction in a BFB as a function of $z / L$ and $r / R$ :

$$
\begin{aligned}
& (1-\varepsilon)_{\mathrm{co}}=0.5627 \exp \left[-0.226-0.4435\left(z / h_{\mathrm{s}}\right)\right], \\
& (1-\varepsilon)_{\text {wo }}=0.5849 \exp \left[-0.0521-0.0408\left(z / h_{\mathrm{s}}\right)\right],
\end{aligned}
$$

$$
\begin{aligned}
& B_{\mathrm{o}}=2.0178 \exp \left[0.099\left(z / h_{\mathrm{s}}\right)-0.0309\right] \\
& \begin{aligned}
(1-\varepsilon)_{\mathrm{o}}= & (1-\varepsilon)_{\mathrm{co}} \\
& +\left[(1-\varepsilon)_{\mathrm{wo}}-(1-\varepsilon)_{\mathrm{co}}\right](r / R)^{B_{\mathrm{o}}} .
\end{aligned}
\end{aligned}
$$

Substitution of $U_{\mathrm{s}} / U_{\mathrm{mf}}=1.42$ and $H=858 \mathrm{~A} / \mathrm{m}$ into Eqs. (11)-(13) and (9) gave local solids fraction in an MBFB as a function of $z / L$ and $r / R$ :

$$
\begin{aligned}
& (1-\varepsilon)_{\mathrm{c}}=0.5361 \exp \left[-0.0635\left(z / h_{\mathrm{s}}\right)\right] \\
& (1-\varepsilon)_{\mathrm{w}}=0.5922 \exp \left[-0.0623\left(z / h_{\mathrm{s}}\right)\right] \\
& B=2.0022+2.0178 \exp \left[0.099\left(z / h_{\mathrm{s}}\right)-0.0309\right] \\
& \quad-1.9287 \exp \left[0.1247\left(z / h_{\mathrm{s}}\right)\right], \\
& (1-\varepsilon)=(1-\varepsilon)_{\mathrm{c}}+\left[(1-\varepsilon)_{\mathrm{w}}-(1-\varepsilon)_{\mathrm{c}}\right](r / R)^{B} .
\end{aligned}
$$

Eqs. (14)-(20) and (9) show that $(1-\varepsilon)_{\mathrm{co}},(1-\varepsilon)_{\mathrm{wo}}$, $B_{\mathrm{o}},(1-\varepsilon)_{\mathrm{c}},(1-\varepsilon)_{\mathrm{w}}$, and $B$ are the exponential functions of $z / L ;(1-\varepsilon)_{0}$ and $(1-\varepsilon)$ are a function of $r / R$. 
In Fig. 24(a) and (b), the upper surface of dense bubbling phase is at $z / L=0.3$ in a BFB and at $z / L=0.25$ in an MBFB. This means that the magnetic field decreases the height of dense bubbling phase. The solids fractions of contour lines in dense bubbling phase were from 0.25 to 0.55 in a BFB and from 0.50 to 0.56 in an MBFB. This means that the magnetic field increases the concentration of dense bubbling phase. The solids fractions of contour lines increased gradually with increasing distance from the axis of bed column and decreasing distance from the distributor in both BFB and MBFB. The contour lines near the bed wall were steeper than that in the central bed region.

As shown in Fig. 24(c), the solids fraction was constant $(=0.5634)$; thus, the particle concentration distributions were uniform in an MSFB.

The effect of the kinds and size of particles on the radial voidage will be investigated in the future work.

\section{Conclusions}

Experimental results of local voidage were obtained in a magnetically fluidized bed for spherical shaped iron particles of size $230 \mu \mathrm{m}$. These results lead to the following conclusions:

(1) An optical method of analysis has been applied successfully to the study of voidage profile in an MFB. The method can be extensively used in both dense and dilute phases.

(2) The local voidage in an MFB is dependent on magnetic field intensity, gas velocity, and the position in the bed. Solids concentration increases with increasing magnetic field intensity, increasing distance from the axis of bed column, decreasing gas velocity, and decreasing distance from the distributor.

(3) The local voidage in a fixed bed remains unchanged at a constant gas velocity. The local voidage in an MSFB changes irregularly with increasing gas velocity. The local voidage in an MBFB changes linearly with increasing air velocity.

(4) The radial voidage profiles in a fluidized bed can be correlated by the expression $(1-\varepsilon)=(1-\varepsilon)_{\mathrm{c}}+[(1-$ $\left.\varepsilon)_{\mathrm{w}}-(1-\varepsilon)_{\mathrm{c}}\right](r / R)^{B}$. The standard deviation of the predicted local solids fraction from the experimental values was only $2 \%$.

(5) By regulating magnetic field intensity and gas velocity, we can make a expectant radial voidage profile, which is one of the following three curves: a curve, which is flat in the central bed region but steep near the bed wall, a parabola and a horizon.

\section{List of symbols \\ A Bed cross-sectional area $\left(\mathrm{m}^{2}\right)$ \\ $B \quad$ Parameter in Eq. (9) (-)}

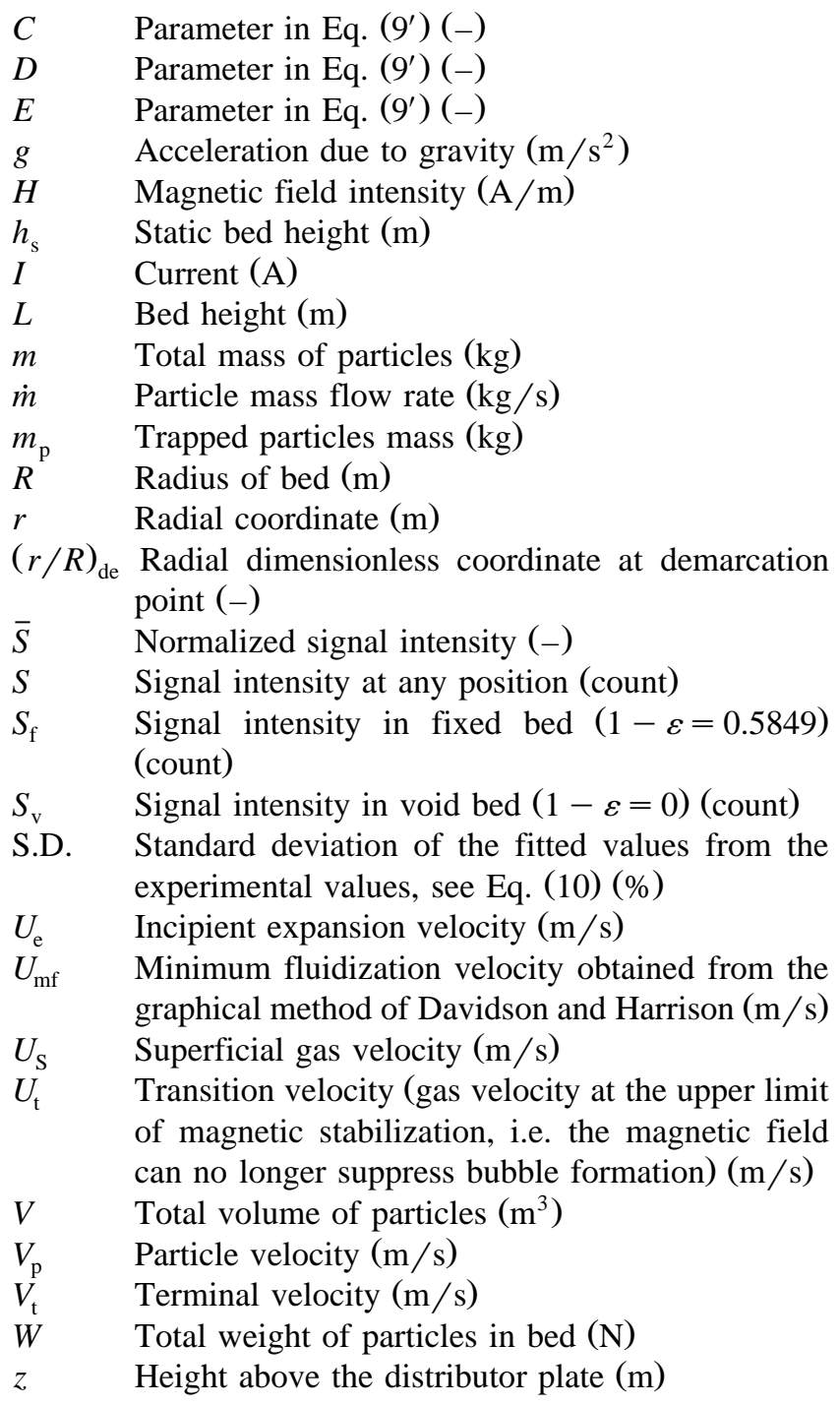

Greek letters

$\Delta L \quad$ Distance between shutter plates or pressure probes (m)

$\Delta P \quad$ Pressure drop $(\mathrm{Pa})$

$\varepsilon \quad$ Local, time-averaged voidage in bed (-)

$\bar{\varepsilon} \quad$ Voidage averaged over bed cross-section (-)

$(1-\varepsilon)_{\mathrm{c}}$ Local, time-averaged voidage at the center of the bed $(-)$

$(1-\varepsilon)_{\mathrm{w}}$ Local, time-averaged voidage at bed wall (-)

$\rho_{\mathrm{p}} \quad$ Particle density $\left(\mathrm{kg} / \mathrm{m}^{3}\right)$
Abbreviations
BFB Bubbling fluidized bed
c.d.f. Cumulative distribution function
MBFB Magnetized bubbling fluidized bed
MFB Magnetofluidized bed
MSFB Magnetically stabilized fluidized bed 
p.d.f. Probability density function

STD Standard deviation of pressure drop fluctuations

$\mathrm{STD}=\sqrt{\frac{\sum\left[(\Delta P)_{i}-\overline{\Delta P}\right]^{2}}{\text { number of data points }-1}}(\mathrm{~Pa})$

$\overline{\Delta P}=\frac{\Sigma(\Delta P)_{i}}{\text { number of data points }}(\mathrm{Pa})$

\section{References}

[1] M.A. Burns, D.J. Graves, Biotechnol. Prog. 1 (1985) 95.

[2] C.H. Lochmuller, L.S. Wigman, Sep. Sci. Technol. 22 (1987) 2111.

[3] J.H. Siegell, G.D. Dupre, J.C. Pirkle Jr., AIChE Symp. Ser. 82 (1986) 128.

[4] A.H. Cohen, C. Tien, Powder Technol. 64 (1991) 147.

[5] M. Warrior, C. Tien, Chem. Eng. Sci. 41 (1986) 1711.

[6] O. Harel, W. Resnick, Y. Zimmels, J. Magn. Magn. Mater. 83 (1990) 498.

[7] O. Harel, Y. Zimmels, W. Resnick, Powder Technol. 64 (1991) 159.

[8] J. Rincon, Sep. Sci. Technol. 28 (1993) 1241.

[9] R.E. Rosensweig, W.K. Lee, J.H. Siegell, Sep. Sci. Technol. 22 (1987) 25.

[10] S.Y. Labroo, Ebrahimi, J.Y. Park, W.J. Yeh, IEEE Trans. Magn. 28 (1992) 1895.

[11] M.A. Burns, D.J. Graves, React. Polym. 6 (1987) 45.

[12] B.E. Terranova, M.A. Burns, Biotechnol. Prog. 5 (1989) 98.

[13] B.E. Terranova, M.A. Burns, Biotechnol. Bioeng. 37 (1991) 110.

[14] P. Geuzens, D. Thoenes, Chem. Eng. Commun. 67 (1988) 229.

[15] V.I. Sikavitsas, R.T. Yang, M.A. Burns, E.J. Langenmayr, Ind. Eng. Chem. Res. 34 (1995) 2873.

[16] I.A. Zrunchev, F. Popova, Powder Technol. 64 (1991) 175.
[17] D. Weng, L. Cheng, Y. Han, W. Zhu, S. Xu, F. Ouyang, AIChE Symp. Ser. 88 (1992) 107.

[18] R.E. Rosensweig, Science 57 (1979) 204.

[19] Y.A. Liu, R.K. Hamby, R.D. Colberg, Powder Technol. 64 (1991) 3.

[20] M.K. Horio, O. Morishita, N. Tachibana, in: P. Basu, J.F. Large (Eds.), Proc. 2nd Int. Conf. Circulating Fluidized Bed Technology, Pergamon, Oxford, 1988, pp. 147-154.

[21] E.-U. Hartge, D. Rensner, J. Werther, in: P. Basu, J.F. Large (Eds.), Proc. 2nd Int. Conf. Circulating Fluidized Bed Technology, Pergamon, Oxford, 1988, pp. 165-180.

[22] P.M. Herbert, T.A. Gauthier, C.L. Briens, M.A. Bergougnou, Powder Technol. 80 (1994) 243.

[23] Y. Tung, J. Li, M. Kwauk, in: M. Kwauk, D. Kunii (Eds.), Third China-Japan Symposium on Fluidization, Beijing, 1988, pp. 139145.

[24] W. Zhang, Y. Tung, F. Johnsson, Chem. Eng. Sci. 46 (1991) 3045.

[25] J.J. Nieuwland, R. Meijer, J.A.M. Kuipers, W.P.M. van Swaaij, Powder Technol. 87 (1996) 127.

[26] J.Y. Hristov, Powder Technol. 97 (1998) 35.

[27] D. Kunii, O. Levenspiel, Fluidization Engineering, Chap. 3, Butterworth-Heinemann, Boston, MA, 1991, 81.

[28] Y. Matsuno, H. Yamaguchi, T. Oka, H. Kage, K. Higashitani, Powder Technol. 36 (1983) 215.

[29] S. Morooka, K. Kawazuishi, Y. Kato, Powder Technol. 26 (1980) 75.

[30] Z.R. Jovanovic, G.N. Jovanovic, Bubble size and fluidization regimes in magnetically controlled fluidized beds, paper no. 28i, paper presented at the 1993 AIChE Annual Meeting, St. Louis, MO, U.S.A., 1993.

[31] M. Puncochar, J. Dvahos, J. Cermak, K. Selucky, Chem. Eng. Commun. 35 (1985) 81.

[32] W.K. Lee, AIChE Symp. Ser. 79 (1983) 87.

[33] I.P. Penchev, J.Y. Hristov, Powder Technol. 62 (1990) 1.

[34] W.K. Lee, Powder Technol. 64 (1991) 69.

[35] J.Y. Hristov, Powder Technol. 87 (1996) 59.

[36] X.-G. Hao, Y.-F. Shi, H.-R. Yu, J. Chem. Ind. Eng. (China) 49 (1998) 362. 